\title{
An Iterative Algorithm for the Generalized Reflexive Solutions of the Generalized Coupled Sylvester Matrix Equations
}

\author{
Feng Yin ${ }^{1}$ and Guang-Xin Huang ${ }^{2}$ \\ ${ }^{1}$ School of Science, Sichuan University of Science and Engineering, Zigong 643000, China \\ ${ }^{2}$ College of Management Science, Geomathematics Key Laboratory of Sichuan Province, \\ Chengdu University of Technology, Chengdu 610059, China
}

Correspondence should be addressed to Feng Yin, fyin@suse.edu.cn

Received 14 November 2011; Revised 13 March 2012; Accepted 25 March 2012

Academic Editor: Alain Miranville

Copyright (C) 2012 F. Yin and G.-X. Huang. This is an open access article distributed under the Creative Commons Attribution License, which permits unrestricted use, distribution, and reproduction in any medium, provided the original work is properly cited.

\begin{abstract}
An iterative algorithm is constructed to solve the generalized coupled Sylvester matrix equations $(A X B-C Y D, E X F-G Y H)=(M, N)$, which includes Sylvester and Lyapunov matrix equations as special cases, over generalized reflexive matrices $X$ and $Y$. When the matrix equations are consistent, for any initial generalized reflexive matrix pair $\left[X_{1}, Y_{1}\right]$, the generalized reflexive solutions can be obtained by the iterative algorithm within finite iterative steps in the absence of round-off errors, and the least Frobenius norm generalized reflexive solutions can be obtained by choosing a special kind of initial matrix pair. The unique optimal approximation generalized reflexive solution pair $[\hat{X}, \widehat{Y}]$ to a given matrix pair $\left[X_{0}, Y_{0}\right]$ in Frobenius norm can be derived by finding the least-norm generalized reflexive solution pair $\left[\tilde{X}^{*}, \tilde{Y}^{*}\right]$ of a new corresponding generalized coupled Sylvester matrix equation pair $(A \tilde{X} B-C \tilde{Y} D, E \tilde{X} F-G \tilde{Y} H)=(\widetilde{M}, \widetilde{N})$, where $\widetilde{M}=M-A X_{0} B+C Y_{0} D, \widetilde{N}=N-E X_{0} F+G Y_{0} H$. Several numerical examples are given to show the effectiveness of the presented iterative algorithm.
\end{abstract}

\section{Introduction}

In this paper, the following notations are used. Let $\mathcal{R}^{m \times n}$ denote the set of all $m \times n$ real matrices. We denote by the superscript $T$ the transpose of a matrix. In matrix space $\mathcal{R}^{m \times n}$, define inner product as $\langle A, B\rangle=\operatorname{tr}\left(B^{T} A\right)$ for all $A, B \in \mathcal{R}^{m \times n}$, where $\operatorname{tr}(A)$ denotes the trace of a matrix $A$. $\|A\|$ represents the Frobenius norm of $A$. $R(A)$ represents the column space of $A$. $\operatorname{vec}(\cdot)$ represents the vector operator, that is, $\operatorname{vec}(A)=\left(\mathbf{a}_{1}^{T}, \mathbf{a}_{2}^{T}, \ldots, \mathbf{a}_{n}^{T}\right)^{T} \in \mathcal{R}^{m n}$ for the matrix $A=\left(\mathbf{a}_{1}, \mathbf{a}_{2}, \ldots, \mathbf{a}_{n}\right) \in \mathcal{R}^{m \times n}, \mathbf{a}_{i} \in R^{m}, i=1,2, \ldots, n . A \otimes B$ stands for the Kronecker product 
of matrices $A$ and $B, \operatorname{diag}(A, B)$ denotes the block diagonal matrix with $A$ and $B$ and being the main diagonal elements orderly. $I_{n}$ denotes the $n$-order identity matrix.

Definition 1.1 (see $[1,2]$ ). A matrix $P \in \mathcal{R}^{n \times n}$ is said to be a generalized reflection matrix if $P$ satisfies that $P^{T}=P, P^{2}=I$.

Definition 1.2 (see [1,2]). Let $P \in \mathcal{R}^{n \times n}$ and $Q \in \mathcal{R}^{n \times n}$ be two generalized reflection matrices. A matrix $A \in \mathcal{R}^{n \times n}$ is called generalized reflexive (or generalized antireflexive) with respect to the matrix pair $(P, Q)$ if $P A Q=A$ (or $P A Q=-A$ ). The set of all $n$-by- $n$ generalized reflexive matrices with respect to matrix pair $(P, Q)$ is denoted by $\mathcal{R}_{r}^{n \times n}(P, Q)$.

The generalized reflexive and antireflexive matrices have many special properties and usefulness in engineering and scientific computations [1-6]. In particular, let $P=Q$, then a generalized reflexive matrix is called a reflexive matrix, which plays an important role in many areas and has been studied in [7-11]. Specially, let $X^{T}=X$, then a reflexive matrix $X$ is called a generalized bisymmetric matrix, which has been studied in $[12,13]$. Moreover, let $P=Q=J_{n}$, then a generalized reflexive matrix is the well-known centrosymmetric matrix, which has been widely and extensively studied in [14-17].

The generalized coupled Sylvester systems play a fundamental role in the various fields of engineering theory, particularly in control systems. The numerical solution of the generalized coupled Sylvester systems has been addressed in a large body of literature. Kågström and Westin [18] developed a generalized Schur method by applying the QZ algorithm to solve $(A X B-C Y D, E X F-G Y H)=(M, N)$. Ding and Chen [19] presented an iterative least squares solutions of $(A X B-C Y D, E X F-G Y H)=(M, N)$ based on a hierarchical identification principle [20], in addition, by applying the hierarchical identification principle, Kılıçman and Zhour [21] developed an iterative algorithm for obtaining the weighted least-squares solution. Recently, some finite iterative algorithms have also been developed to solve matrix equations. For more detail, we refer to [11, 13, 22-30]. Wang $[31,32]$ gave the bi(skew)symmetric and centrosymmetric solutions to the system of quaternion matrix equations $A_{1} X=C_{1}, A_{3} X B_{3}=C_{3}$. Wang [33] also solved a system of matrix equations over arbitrary regular rings with identity. Chang and Wang [34] gave the necessary and sufficient conditions for the existence of and the expressions for the symmetric solutions of the matrix equations $A X+Y A=C, A X A^{T}+B Y B^{T}=C$, and $\left(A^{T} X A, B^{T} X B\right)=(C, D)$. Ding and Chen [25] also presented the gradient-based iterative algorithms by applying the gradient search principle and the hierarchical identification principle for the general coupled matrix equations $\sum_{j=1}^{p} A_{i j} X_{j} B_{i j}=M_{i}, i=1,2, \ldots, p$. Zhou et al. [35] proposed gradient-based iterative algorithms for solving the general coupled matrix equations with weighted least squares solutions. Wu et al. [36, 37] gave the finite iterative solutions to coupled Sylvester-conjugate matrix equations. Wu et al. [38] gave the finite iterative solutions to a class of complex matrix equations with conjugate and transpose of the unknowns. Jonsson and Kågström [39] proposed recursive block algorithms for solving the one-sided and coupled Sylvester matrix equations $(A X-Y B, D X-Y E)=(C, F)$. Jonsson and Kågström [40] also proposed recursive block algorithms for the two-sided and generalized Sylvester and Lyapunov matrix equations. Dehghan and Hajarian $[7,8]$ gave the reflexive and generalized bisymmetric matrices solutions of the generalized coupled Sylvester matrix equations $(A Y-Z B, C Y-Z D)=(E, F)$. Very recently, Dehghan and Hajarian [12] constructed an iterative algorithm to solve the generalized coupled Sylvester matrix equations $(A X B+C Y D, E X F+G Y H)=(M, N)$ over generalized bisymmetric matrices. 
Huang et al. [13] present an iterative algorithm for the generalized coupled Sylvester matrix equations $(A Y-Z B, C Y-Z D)=(E, F)$ and its optimal approximation problem over generalized reflexive matrices solutions. In [30], the similar but different iterative algorithm is constructed to solve the generalized coupled Sylvester matrix equations ( $A X B-C Y D, E X F-$ $G Y H)=(M, N)$ and the optimal approximation problem over reflexive matrices. However, the generalized coupled Sylvester matrix equations $(A X B-C Y D, E X F-G Y H)=(M, N)$ and the optimal approximation over generalized reflexive matrices have not been solved.

In this paper, we will consider the following two problems.

Problem 1. Let $P \in \mathcal{R}^{m \times m}, Q \in \mathcal{R}^{n \times n}, R \in \mathcal{R}^{s \times s}$, and $S \in \mathcal{R}^{t \times t}$ be generalized reflection matrices. For given matrices $A \in \mathcal{R}^{p \times m}, B \in \mathcal{R}^{n \times q}, C \in \mathcal{R}^{p \times s}, D \in \mathcal{R}^{1 \times q}, M \in \mathcal{R}^{p \times q}, E \in \mathcal{R}^{k \times m}, F \in$ $\mathcal{R}^{n \times l}, G \in \mathcal{R}^{k \times s}, H \in \mathcal{R}^{t \times l}, N \in \mathcal{R}^{k \times l}$, find a pair of matrices $X \in \mathcal{R}_{r}^{m \times n}(P, Q), Y \in \mathcal{R}_{r}^{s \times t}(R, S)$ such that

$$
\begin{aligned}
& A X B-C Y D=M, \\
& E X F-G Y H=N .
\end{aligned}
$$

Problem 2. When Problem 1 is consistent, let $S_{E}$ denote the set of the generalized reflexive solutions of Problem 1, that is,

$$
S_{E}=\left\{[X, Y] \mid A X B-C Y D=M, E X F-G Y H=N, Y \in \mathcal{R}_{r}^{m \times n}(P, Q), Z \in \mathcal{R}_{r}^{s \times t}(R, S)\right\} .
$$

For a given matrix pair $\left[Y_{0}, Z_{0}\right] \in \mathcal{R}_{r}^{m \times n}(P, Q) \times \mathcal{R}_{r}^{s \times t}(R, S)$, find $[\widehat{Y}, \widehat{Z}] \in S_{E}$ such that

$$
\left\|\widehat{Y}-Y_{0}\right\|^{2}+\left\|\hat{Z}-Z_{0}\right\|^{2}=\min _{[Y, Z] \in S_{E}}\left\{\left\|Y-Y_{0}\right\|^{2}+\left\|Z-Z_{0}\right\|^{2}\right\} .
$$

The two-sided and generalized coupled Sylvester matrix equations (1.1) play a fundamental role in wide applications in several areas, such as stability theory, control theory, perturbation analysis, and some other fields of pure and applied mathematics. In addition, as special type of generalized coupled Sylvester matrix equations (1.1), the generalized Sylvester matrix equation $(A X-Y B, C X-Y D)=(E, F)$ arises in computing the deflating subspace of descriptor linear systems [18]. Wu et al. [36] presented some examples to show a motivation for studying (1.1). Problem 2 occurs frequently in experiment design, see for instance [41].

This paper is organized as follows. In Section 2, we will solve Problem 1 by constructing an iterative algorithm, that is, if Problem 1 is consistent, then for an arbitrary initial matrix pair $\left[Y_{1}, Z_{1}\right] \in \mathcal{R}_{r}^{m \times n}(P, Q) \times \mathcal{R}_{r}^{s \times t}(R, S)$, we can obtain a solution pair $\left[Y^{*}, Z^{*}\right]$ of Problem 1 within finite iterative steps in the absence of round-off errors. Let $X_{1}=$ $A^{T} K B^{T}+E^{T} L F^{T}+P A^{T} K B^{T} Q+P E^{T} L F^{T} Q$ and $Y_{1}=-C^{T} K D^{T}-G^{T} L H^{T}-R C^{T} K D^{T} S-R G^{T} L H^{T} S$, where $K \in R^{p \times q}, L \in R^{k \times l}$ are arbitrary matrices, or more especially, let $X_{1}=0$ and $Y_{1}=0$, we can obtain the least Frobenius norm solutions of Problem 1. Then, in Section 3, we give the optimal approximate solution pair of Problem 2 by finding the least Frobenius norm generalized reflexive solution pair of the corresponding generalized coupled Sylvester matrix equations. In Section 4, several numerical examples are given to illustrate the application of our method. At last, some conclusions are drawn in Section 5. 


\section{An Iterative Algorithm for Solving Problem 1}

In this section, we will first introduce an iterative algorithm to solve Problem 1, then prove that it is convergent. Then, we will give the least-norm generalized reflexive solutions of Problem 1 when an appropriate initial iterative matrix pair is chosen.

For the purpose of simplification, we introduce the following operators:

$$
\begin{aligned}
& \Phi(X, Y)=A X B-C Y D \\
& \Psi(X, Y)=E X F-G Y H .
\end{aligned}
$$

Algorithm 2.1. We have the following steps.

Step 1. Input matrices $A \in \mathcal{R}^{p \times m}, B \in \mathcal{R}^{n \times q}, C \in \mathcal{R}^{p \times s}, D \in \mathcal{R}^{t \times q}, M \in \mathcal{R}^{p \times q}, E \in \mathcal{R}^{k \times m}, F \in$ $\mathcal{R}^{n \times l}, G \in \mathcal{R}^{k \times s}, H \in \mathcal{R}^{t \times l}, N \in \mathcal{R}^{k \times l}$, and four generalized reflection matrices $P \in \mathcal{R}^{m \times m}, Q \in$ $\mathcal{R}^{n \times n}, R \in \mathcal{R}^{s \times s}, S \in \mathcal{R}^{t \times t}$.

Step 2. Choose two arbitrary matrices $X_{1} \in \mathcal{R}_{r}^{m \times n}(P, Q), Y_{1} \in \mathcal{R}_{r}^{s \times t}(R, S)$. Compute

$$
\begin{aligned}
& R_{1}= \operatorname{diag}\left(M-\Phi\left(X_{1}, Y_{1}\right), N-\Psi\left(X_{1}, Y_{1}\right)\right), \\
& \begin{aligned}
U_{1}=\frac{1}{2}[ & A^{T}\left(M-\Phi\left(X_{1}, Y_{1}\right)\right) B^{T}+E^{T}\left(N-\Psi\left(X_{1}, Y_{1}\right)\right) F^{T} \\
& \left.+P A^{T}\left(M-\Phi\left(X_{1}, Y_{1}\right)\right) B^{T} Q+P E^{T}\left(N-\Psi\left(X_{1}, Y_{1}\right)\right) F^{T} Q\right],
\end{aligned} \\
& \begin{aligned}
& V_{1}=\frac{1}{2}[-C^{T}\left(M-\Phi\left(X_{1}, Y_{1}\right)\right) D^{T}-G^{T}\left(N-\Psi\left(X_{1}, Y_{1}\right)\right) H^{T} \\
&\left.\quad-R C^{T}\left(M-\Phi\left(X_{1}, Y_{1}\right)\right) D^{T} S-R G^{T}\left(N-\Psi\left(X_{1}, Y_{1}\right)\right) H^{T} S\right], \\
& k:=1 .
\end{aligned}
\end{aligned}
$$

Step 3. If $R_{k}=0$, then stop and $\left[X_{k}, Y_{k}\right]$ is the solution of the generalized coupled Sylvester matrix equation (1.1); else if $R_{k} \neq 0$, but $U_{k}=0$ and $V_{k}=0$, then stop and the generalized coupled Sylvester matrix equations (1.1) are not consistent over generalized reflexive matrices; else $k:=k+1$.

Step 4. Compute

$$
\begin{aligned}
X_{k} & =X_{k-1}+\frac{\left\|R_{k-1}\right\|^{2}}{\left\|U_{k-1}\right\|^{2}+\left\|V_{k-1}\right\|^{2}} U_{k-1}, \\
Y_{k} & =Y_{k-1}+\frac{\left\|R_{k-1}\right\|^{2}}{\left\|U_{k-1}\right\|^{2}+\left\|V_{k-1}\right\|^{2}} V_{k-1}, \\
R_{k} & =\operatorname{diag}\left(M-\Phi\left(X_{k}, Y_{k}\right), N-\Psi\left(X_{k}, Y_{k}\right)\right) \\
& =R_{k-1}-\frac{\left\|R_{k-1}\right\|^{2}}{\left\|U_{k-1}\right\|^{2}+\left\|V_{k-1}\right\|^{2}} \operatorname{diag}\left(\Phi\left(U_{k-1}, V_{k-1}\right), \Psi\left(U_{k-1}, V_{k-1}\right)\right),
\end{aligned}
$$




$$
\begin{aligned}
U_{k}=\frac{1}{2}[ & A^{T}\left(M-\Phi\left(X_{k}, Y_{k}\right)\right) B^{T}+E^{T}\left(N-\Psi\left(X_{k}, Y_{k}\right)\right) F^{T} \\
& \left.+P A^{T}\left(M-\Phi\left(X_{k}, Y_{k}\right)\right) B^{T} Q+P E^{T}\left(N-\Psi\left(X_{k}, Y_{k}\right)\right) F^{T} Q\right]+\frac{\left\|R_{k}\right\|^{2}}{\left\|R_{k-1}\right\|^{2}} U_{k-1} \\
V_{k}=\frac{1}{2}[ & -C^{T}\left(M-\Phi\left(X_{k-1}, Y_{k-1}\right)\right) D^{T}-G^{T}\left(N-\Psi\left(X_{k-1}, Y_{k-1}\right)\right) H^{T} \\
& \left.-R C^{T}\left(M-\Phi\left(X_{k-1}, Y_{k-1}\right)\right) D^{T} S-R G^{T}\left(N-\Psi\left(X_{k-1}, Y_{k-1}\right)\right) H^{T} S\right]+\frac{\left\|R_{k}\right\|^{2}}{\left\|R_{k-1}\right\|^{2}} V_{K-1}
\end{aligned}
$$

Step 5. Go to Step 3.

Obviously, it can be seen that $X_{k}, U_{k} \in R_{r}^{m \times n}(P, Q), Y_{k}, V_{k} \in R_{r}^{s \times t}(R, S)$, where $k=$ $1,2, \ldots$

Lemma 2.2. For the sequences $\left\{R_{i}\right\},\left\{U_{i}\right\}$, and $\left\{V_{i}\right\}$ generated by Algorithm 2.1, and $s \geq 2$, we have

$$
\operatorname{tr}\left(R_{i}^{T} R_{j}\right)=0, \quad \operatorname{tr}\left(U_{i}^{T} U_{j}+V_{i}^{T} V_{j}\right)=0, \quad i, j=1,2, \ldots, s, i \neq j
$$

The proof of Lemma 2.2 is presented in Appendix A.

Lemma 2.3. Suppose $\left[X^{*}, Y^{*}\right]$ is an arbitrary solution pair of Problem 1, then for any initial generalized reflexive matrix pair $\left[X_{1}, Y_{1}\right]$, we have

$$
\operatorname{tr}\left(\left(X^{*}-X_{i}\right)^{T} U_{i}+\left(Y^{*}-Y_{i}\right)^{T} V_{i}\right)=\left\|R_{i}\right\|^{2}, \quad k=1,2, \ldots,
$$

where the sequences $\left\{X_{i}\right\},\left\{Y_{i}\right\},\left\{U_{i}\right\},\left\{V_{i}\right\}$, and $\left\{R_{i}\right\}$ are generated by Algorithm 2.1.

The proof of Lemma 2.3 is presented in Appendix B.

Remark 2.4. If there exist, a positive number $k$ such that $U_{k}=0$ and $V_{k}=0$ but $R_{k} \neq 0$, then by Lemma 2.3, we have that the generalized coupled Sylvester matrix equations (1.1) are not consistent over generalized reflexive matrices.

Theorem 2.5. Suppose that Problem 1 is consistent, then for an arbitrary initial matrix pair $\left[X_{1}, Y_{1}\right] \in \mathcal{R}_{r}^{m \times n}(P, Q) \times \mathcal{R}_{r}^{s \times t}(R, S)$, a generalized reflexive solution pair of Problem 1 can be obtained with finite iteration steps in the absence of round-off errors.

Proof. If $R_{i} \neq \mathbf{0}, i=1,2, \ldots, p q+s t$, by Lemma 2.3 , we have $U_{i} \neq \mathbf{0}, V_{i} \neq \mathbf{0}, i=1,2, \ldots, p q+s t$, then we can compute $\left[X_{p q+s t+1}, Y_{p q+s t+1}\right]$ by Algorithm 2.1.

By Lemma 2.2, we have

$$
\begin{aligned}
& \operatorname{tr}\left(R_{p q+s t+1}^{T} R_{i}\right)=0, \quad i=1,2, \ldots, p q+s t \\
& \operatorname{tr}\left(R_{i}^{T} R_{j}\right)=0, \quad i, j=1,2, \ldots, p q+s t, i \neq j .
\end{aligned}
$$



subspace

It can be seen that the set of $R_{1}, R_{2}, \ldots, R_{p q+s t}$ is an orthogonal basis of the matrix

$$
S=\left\{L \mid L=\operatorname{diag}\left(L_{1}, L_{2}\right), L_{1} \in \mathcal{R}^{p \times q}, L_{2} \in \mathcal{R}^{s \times t}\right\},
$$

which implies that $R_{p q+s t+1}=0$, that is, $\left[X_{p q+s t+1}, Y_{p q+s t+1}\right] \in \mathcal{R}_{r}^{m \times n}(P, Q) \times \mathcal{R}_{r}^{s \times t}(R, S)$ is a solution pair of Problem 1. This completes the proof.

To show the least Frobenius norm generalized reflexive solutions of Problem 1, we first introduce the following result.

Lemma 2.6 (see [42, Lemma 2.4]). Suppose that the consistent system of linear equation $A x=b$ has a solution $x^{*} \in R\left(A^{T}\right)$, then $x^{*}$ is a unique least Frobenius norm solution of the system of linear equation.

By Lemma 2.6, the following result can be obtained.

Theorem 2.7. Suppose that Problem 1 is consistent. If we choose the initial iterative matrices $X_{1}=$ $A^{T} K B^{T}+E^{T} L F^{T}+P A^{T} K B^{T} Q+P E^{T} L F^{T} Q$ and $Y_{1}=-C^{T} K D^{T}-G^{T} L H^{T}-R C^{T} K D^{T} S-R G^{T} L H^{T} S$, where $K \in \mathcal{R}^{p \times q}, L \in R^{k \times l}$ are arbitrary matrices, especially, $X_{1}=0 \in \mathcal{R}^{m \times n}(P, Q)$ and $Y_{1}=0 \in$ $R^{s \times t}(R, S)$, then the solution pair $\left[Y^{*}, Z^{*}\right]$ generated by Algorithm 2.1 is the unique least Frobenius norm generalized reflexive solutions of Problem 1.

Proof. We know the solvability of the generalized coupled Sylvester matrix equations (1.1) over generalized reflexive matrices is equivalent to the following matrix equations:

$$
\begin{gathered}
A X B-C Y D=M, \\
E X F-G Y H=N, \\
A P X Q B-C R Y S D=M, \\
E P X Q F-G R Y S H=N .
\end{gathered}
$$

Then, the system of matrix equations (2.8) is equivalent to

$$
\left(\begin{array}{cc}
B^{T} \otimes A & -D^{T} \otimes C \\
F^{T} \otimes E & -H^{T} \otimes G \\
B^{T} Q \otimes A P & -D^{T} S \otimes C R \\
F^{T} Q \otimes E P & -H^{T} S \otimes G R
\end{array}\right)\left(\begin{array}{c}
\operatorname{vec}(X) \\
\operatorname{vec}(Y)
\end{array}\right)=\left(\begin{array}{c}
\operatorname{vec}(M) \\
\operatorname{vec}(N) \\
\operatorname{vec}(M) \\
\operatorname{vec}(N)
\end{array}\right)
$$


Let $X_{1}=A^{T} K B^{T}+E^{T} L F^{T}+P A^{T} K B^{T} Q+P E^{T} L F^{T} Q$ and $Y_{1}=-C^{T} K D^{T}-G^{T} L H^{T}-R C^{T} K D^{T} S-$ $R G^{T} L H^{T} S$, where $K \in \mathcal{R}^{p \times q}, L \in \mathcal{R}^{k \times l}$ are arbitrary matrices, then

$$
\begin{aligned}
& \left(\begin{array}{c}
\operatorname{vec}\left(X_{1}\right) \\
\operatorname{vec}\left(Y_{1}\right)
\end{array}\right)=\left(\begin{array}{c}
\operatorname{vec}\left(A^{T} K B^{T}+E^{T} L F^{T}+P A^{T} K B^{T} Q+P E^{T} L F^{T} Q\right) \\
\operatorname{vec}\left(-C^{T} K D^{T}-G^{T} L H^{T}-R C^{T} K D^{T} S-R G^{T} L H^{T} S\right)
\end{array}\right) \\
& =\left(\begin{array}{cccc}
B \otimes A^{T} & F \otimes E^{T} & Q B \otimes P A^{T} & Q F \otimes P E^{T} \\
-D \otimes C^{T} & -H \otimes G^{T} & -S D \otimes R C^{T} & -S H \otimes R G^{T}
\end{array}\right)\left(\begin{array}{c}
\operatorname{vec}(K) \\
\operatorname{vec}(L) \\
\operatorname{vec}(K) \\
\operatorname{vec}(L)
\end{array}\right) \\
& =\left(\begin{array}{cc}
B^{T} \otimes A & -D^{T} \otimes C \\
F^{T} \otimes E & -H^{T} \otimes G \\
B^{T} Q \otimes A P & -D^{T} S \otimes C R \\
F^{T} Q \otimes E P & -H^{T} S \otimes G R
\end{array}\right)^{T}\left(\begin{array}{c}
\operatorname{vec}(K) \\
\operatorname{vec}(G) \\
\operatorname{vec}(K) \\
\operatorname{vec}(G)
\end{array}\right) \\
& \in R\left(\left(\begin{array}{cc}
B^{T} \otimes A & -D^{T} \otimes C \\
F^{T} \otimes E & -H^{T} \otimes G \\
B^{T} Q \otimes A P & -D^{T} S \otimes C R \\
F^{T} Q \otimes E P & -H^{T} S \otimes G R
\end{array}\right)^{T}\right) .
\end{aligned}
$$

Furthermore, we can see that all $X_{k}, Y_{k}$ generated by Algorithm 2.1 satisfy

$$
\left(\begin{array}{c}
\operatorname{vec}\left(X_{k}\right) \\
\operatorname{vec}\left(Y_{k}\right)
\end{array}\right) \in \mathcal{R}\left(\left(\begin{array}{cc}
B^{T} \otimes A & -D^{T} \otimes C \\
F^{T} \otimes E & -H^{T} \otimes G \\
B^{T} Q \otimes A P & -D^{T} S \otimes C R \\
F^{T} Q \otimes E P & -H^{T} S \otimes G R
\end{array}\right)^{T}\right)
$$

by Lemma 2.6, we know that $\left[X^{*}, Y^{*}\right]$ is the least Frobenius norm generalized reflexive solution pair of the system of linear equations (2.9). Since vector operator is isomorphic, $\left[X^{*}, Y^{*}\right]$ is the unique least Frobenius norm generalized reflexive solution pair of the system of matrix equations (2.8), then $\left[X^{*}, Y^{*}\right]$ is the unique least Frobenius norm generalized reflexive solution pair of Problem 1 .

\section{The Solution of Problem 2}

In this section, we will show that the optimal approximate solutions of Problem 2 for a given generalized reflexive matrix pair can be derived by finding the least Frobenius norm generalized reflexive solutions of the corresponding generalized coupled Sylvester matrix equations. 
When Problem 1 is consistent, the set of generalized reflexive solutions of Problem 1 denoted by $S_{E}$ is not empty. For a given matrix pair $\left[X_{0}, Y_{0}\right] \in \mathcal{R}_{r}^{m \times n}(P, Q) \times \mathcal{R}_{r}^{s \times t}(R, S)$, we have

$$
\left\{\begin{array} { l } 
{ A X B - C Y D = M } \\
{ E X F - G Y H = N }
\end{array} \Longleftrightarrow \left\{\begin{array}{l}
A\left(X-X_{0}\right) B-C\left(Y-Y_{0}\right) D=M-A X_{0} B+C Y_{0} D \\
E\left(X-X_{0}\right) F-G\left(Y-Y_{0}\right) H=N-E X_{0} F+G Y_{0} H
\end{array}\right.\right.
$$

Set $\tilde{X}=X-X_{0}, \tilde{Y}=Y-Y_{0}, \widetilde{M}=M-A X_{0} B+C Y_{0} D, \widetilde{N}=N-E X_{0} F+G Y_{0} H$, then Problem 2 is equivalent to that of finding the least Frobenius norm generalized reflexive solutions pair $\left[\tilde{X}^{*}, \tilde{Y}^{*}\right]$ of the corresponding generalized coupled Sylvester matrix equations

$$
\begin{aligned}
& A \tilde{X} B-C \tilde{Y} D=\widetilde{M}, \\
& E \tilde{X} F-G \tilde{Y} H=\widetilde{N} .
\end{aligned}
$$

By using Algorithm 2.1, let initial iteration matrix $\tilde{X}_{1}=A^{T} K B^{T}+E^{T} L F^{T}+P A^{T} K B^{T} Q+$ $P E^{T} L F^{T} Q$ and $\tilde{Y}_{1}=-C^{T} K D^{T}-G^{T} L H^{T}-R C^{T} K D^{T} S-R G^{T} L H^{T} S$, or more especially, let $\tilde{X}_{1}=0 \in \mathcal{R}_{r}^{m \times n}(P, Q)$ and $\tilde{Y}_{1}=0 \in \mathcal{R}_{r}^{s \times t}(R, S)$, then we can get the least Frobenius norm generalized reflexive solution pair $\left[\tilde{X}^{*}, \tilde{Y}^{*}\right]$ of (3.2). Thus, the generalized reflexive solution pair of the problem 2 can be represented as $[\hat{X}, \widehat{Y}]=\left[\tilde{X}^{*}+X_{0}, \tilde{Y}^{*}+Y_{0}\right]$.

\section{Numerical Experiments}

In this section, we will show several numerical examples to illustrate our results. All the tests are performed by MATLAB 7.8.

Example 4.1. Consider the generalized reflexive solutions of the generalized coupled Sylvester matrix equations $A X B-C Y D=M, E X Y-G Y H=N$, where

$$
\begin{aligned}
A & =\left(\begin{array}{ccccc}
1 & 3 & -5 & 7 & -9 \\
2 & 0 & 4 & 6 & -1 \\
0 & -2 & 9 & 6 & -8 \\
3 & 6 & 2 & 2 & -3 \\
-5 & 5 & -22 & -1 & -11 \\
8 & 4 & -6 & -9 & -9
\end{array}\right), \\
C & =\left(\begin{array}{cccc}
6 & -5 & 7 & -9 \\
2 & 4 & 6 & -11 \\
9 & -12 & 3 & -8 \\
13 & 6 & 4 & -15 \\
-5 & 15 & -13 & -11 \\
2 & 9 & -6 & -9
\end{array}\right),
\end{aligned}
$$


Journal of Applied Mathematics

$$
\begin{aligned}
& E=\left(\begin{array}{ccccc}
14 & 5 & -1 & 7 & 1 \\
-2 & 3 & -2 & 5 & 4 \\
13 & 4 & 2 & -3 & 6 \\
-8 & 1 & -5 & 4 & 8
\end{array}\right), \quad F=\left(\begin{array}{ccccc}
1 & 3 & -5 & 8 & 2 \\
-11 & 5 & -6 & 2 & 5 \\
13 & 2 & 7 & -9 & 7 \\
-9 & 6 & -5 & 12 & 1
\end{array}\right), \\
& G=\left(\begin{array}{cccc}
1 & 2 & -5 & 8 \\
-5 & 5 & -7 & 3 \\
2 & 4 & 9 & -6 \\
-3 & 7 & -12 & 11
\end{array}\right), \quad H=\left(\begin{array}{ccccc}
2 & 4 & 8 & -5 & 4 \\
7 & -1 & 5 & -2 & 3 \\
6 & 3 & 9 & 2 & -6 \\
5 & -2 & 7 & -8 & 1 \\
1 & 4 & -3 & -2 & 6
\end{array}\right), \\
& M=\left(\begin{array}{cccc}
519 & 1177 & 1701 & 1632 \\
-103 & 1583 & -100 & 2382 \\
82 & 1800 & 1029 & 3308 \\
-514 & 839 & -493 & 2458 \\
-753 & 1132 & 2683 & -762 \\
-1164 & 258 & 858 & 408
\end{array}\right), \quad N=\left(\begin{array}{ccccc}
-2426 & 964 & -2653 & 2092 & 603 \\
-65 & 247 & -919 & 291 & 788 \\
-1331 & 1547 & -17 & 992 & 712 \\
-1684 & -659 & -2730 & 1756 & -765
\end{array}\right)
\end{aligned}
$$

Let

$$
\begin{aligned}
& P=\left(\begin{array}{ccccc}
0 & 0 & 0 & 0 & -1 \\
0 & 0 & 0 & 1 & 0 \\
0 & 0 & -1 & 0 & 0 \\
0 & 1 & 0 & 0 & 0 \\
-1 & 0 & 0 & 0 & 0
\end{array}\right), \quad Q=\left(\begin{array}{cccc}
0 & 0 & 1 & 0 \\
0 & 0 & 0 & -1 \\
1 & 0 & 0 & 0 \\
0 & -1 & 0 & 0
\end{array}\right), \\
& R=\left(\begin{array}{cccc}
0 & 0 & 0 & 1 \\
0 & 1 & 0 & 0 \\
0 & 0 & -1 & 0 \\
1 & 0 & 0 & 0
\end{array}\right), \quad S=\left(\begin{array}{ccccc}
0 & 0 & 0 & 1 & 0 \\
0 & 0 & 0 & 0 & 1 \\
0 & 0 & -1 & 0 & 0 \\
1 & 0 & 0 & 0 & 0 \\
0 & 1 & 0 & 0 & 0
\end{array}\right)
\end{aligned}
$$

be generalized reflection matrices. 
We will find the generalized reflexive solutions of the matrix equations $A X B-C Y D=$ $M, E X Y-G Y H=N$ by using Algorithm 2.1. It can be verified that the matrix equations are consistent over generalized reflexive matrices and the solutions are

$$
X^{*}=\left(\begin{array}{cccc}
-2 & 9 & 2 & 5 \\
3 & 1 & 11 & -1 \\
7 & 3 & -7 & 3 \\
11 & 1 & 3 & -1 \\
-2 & 5 & 2 & 9
\end{array}\right), \quad Y^{*}=\left(\begin{array}{ccccc}
14 & 16 & -1 & 3 & 4 \\
9 & 7 & 0 & 9 & 7 \\
-3 & -8 & -8 & 3 & 8 \\
3 & 4 & 1 & 14 & 16
\end{array}\right)
$$

Because of the influence of the error of calculation, the residual $R_{i}$ is usually unequal to zero in the process of the iteration, where $i=1,2, \ldots$. For any chosen positive number $\varepsilon$; however, small enough, for example, $\varepsilon=1.0000 e-010$, whenever $\left\|R_{k}\right\|<\varepsilon$, stop the iteration, $X_{k}$ and $Y_{k}$ are regarded to be generalized reflexive solutions of the matrix equations $A X B-$ $C Y D=M, E X Y-G Y H=N$. Choose an initially iterative matrix pair $\left[X_{1}, Y_{1}\right] \in \mathcal{R}_{r}^{5} \times 4(P, Q) \times$ $R_{r}^{4} \times 5(R, S)$, such as

$$
X_{1}=\left(\begin{array}{cccc}
-1 & 2 & 2 & 4 \\
6 & -1 & 3 & 2 \\
7 & 8 & -7 & 8 \\
3 & -2 & 6 & 1 \\
-2 & 4 & 1 & 2
\end{array}\right), \quad Y_{1}=\left(\begin{array}{ccccc}
3 & 4 & -1 & 3 & 7 \\
9 & 1 & 0 & 9 & 1 \\
-3 & 1 & -8 & 3 & -1 \\
3 & 7 & 1 & 3 & 4
\end{array}\right)
$$

By Algorithm 2.1, we have

$$
\begin{gathered}
X_{30}=\left(\begin{array}{cccc}
-2.0000 & 9.0000 & 2.0000 & 5.0000 \\
3.0000 & 1.0000 & 11.0000 & -1.0000 \\
7.0000 & 3.0000 & -7.0000 & 3.0000 \\
11.0000 & 1.0000 & 3.0000 & -1.0000 \\
-2.0000 & 5.0000 & 2.0000 & 9.0000
\end{array}\right), \\
Y_{30}=\left(\begin{array}{ccccc}
14.0000 & 16.0000 & -1.0000 & 3.0000 & 4.0000 \\
9.0000 & 7.0000 & 0 & 9.0000 & 7.0000 \\
-3.0000 & -8.0000 & -8.0000 & 3.0000 & 8.0000 \\
3.0000 & 4.0000 & 1.0000 & 14.0000 & 16.0000
\end{array}\right), \\
\left\|R_{30}\right\|=2.9703 e-012<\varepsilon .
\end{gathered}
$$

So we obtain the generalized reflexive solutions of the matrix equations $A X B-C Y D=$ $M, E X Y-G Y H=N$. The relative error of the solutions and the residual are shown in 
Figure 1, where the relative error $R E k=\left(\left\|X_{k}-X^{*}\right\|+\left\|Y_{k}-Y^{*}\right\|\right) /\left(\left\|X^{*}\right\|+\left\|Y^{*}\right\|\right)$ and the residual $R k=\left\|R_{k}\right\|$.

Let

$$
X_{1}=\left(\begin{array}{llll}
0 & 0 & 0 & 0 \\
0 & 0 & 0 & 0 \\
0 & 0 & 0 & 0 \\
0 & 0 & 0 & 0 \\
0 & 0 & 0 & 0
\end{array}\right), \quad Y_{1}=\left(\begin{array}{lllll}
0 & 0 & 0 & 0 & 0 \\
0 & 0 & 0 & 0 & 0 \\
0 & 0 & 0 & 0 & 0 \\
0 & 0 & 0 & 0 & 0
\end{array}\right),
$$

by Algorithm 2.1, we have

$$
\begin{gathered}
X^{*}=X_{30}=\left(\begin{array}{cccc}
-2.0000 & 9.0000 & 2.0000 & 5.0000 \\
3.0000 & 1.0000 & 11.0000 & -1.0000 \\
7.0000 & 3.0000 & -7.0000 & 3.0000 \\
11.0000 & 1.0000 & 3.0000 & -1.0000 \\
-2.0000 & 5.0000 & 2.0000 & 9.0000
\end{array}\right), \\
Y^{*}=Y_{30}=\left(\begin{array}{ccccc}
14.0000 & 16.0000 & -1.0000 & 3.0000 & 4.0000 \\
9.0000 & 7.0000 & 0 & 9.0000 & 7.0000 \\
-3.0000 & -8.0000 & -8.0000 & 3.0000 & 8.0000 \\
3.0000 & 4.0000 & 1.0000 & 14.0000 & 16.0000
\end{array}\right), \\
\left\|R_{30}\right\|=8.2565 e-012<\varepsilon .
\end{gathered}
$$

The relative error of the solutions and the residual are shown in Figure 2.

Example 4.2. Consider the unique least-norm generalized reflexive solutions of the matrix equations in Example 4.1. Let

$$
\begin{gathered}
K=\left(\begin{array}{cccc}
1 & 0 & 1 & 2 \\
0 & -1 & 0 & 1 \\
1 & -1 & 0 & 1 \\
2 & 0 & 1 & -3 \\
0 & 1 & 2 & 1 \\
-1 & 0 & -2 & -1
\end{array}\right), \quad L=\left(\begin{array}{ccccc}
-1 & 1 & -1 & 0 & 5 \\
0 & 1 & -1 & 3 & 2 \\
1 & -1 & -2 & 0 & 3 \\
2 & 0 & 1 & -3 & 6
\end{array}\right) \\
X_{1}=A^{T} K B^{T}+C^{T} L D^{T}+P A^{T} K B^{T} Q+P C^{T} L D^{T} Q \\
Y_{1}=-E^{T} K F^{T}-G^{T} L H^{T}-R E^{T} K F^{T} S-R G^{T} L H^{T} S .
\end{gathered}
$$




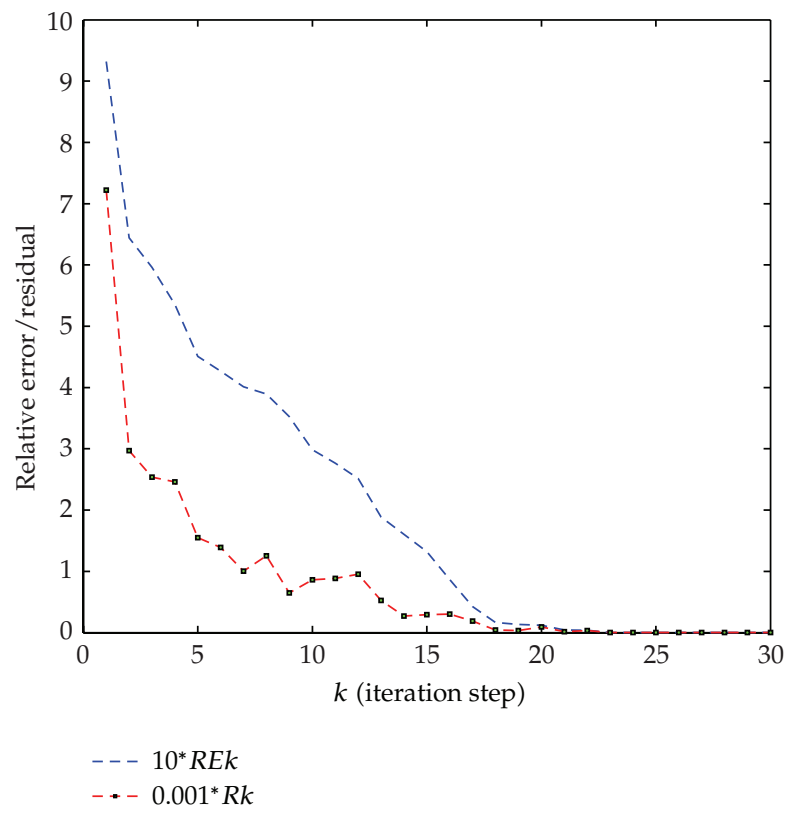

Figure 1: The relative error of the solutions and the residual for Example 4.1 with $X_{1} \neq 0, Y_{1} \neq 0$.

By using Algorithm 2.1, we have the least-norm generalized reflexive solutions of the matrix equations $A X B-C Y D=M, E X Y-G Y H=N$ as follows:

$$
X^{*}=X_{30}=\left(\begin{array}{rrrr}
-2.0000 & 9.0000 & 2.0000 & 5.0000 \\
3.0000 & 1.0000 & 11.0000 & -1.0000 \\
7.0000 & 3.0000 & -7.0000 & 3.0000 \\
11.0000 & 1.0000 & 3.0000 & -1.0000 \\
-2.0000 & 5.0000 & 2.0000 & 9.0000
\end{array}\right),
$$

The relative error of the solutions and the residual are shown in Figure 3. 


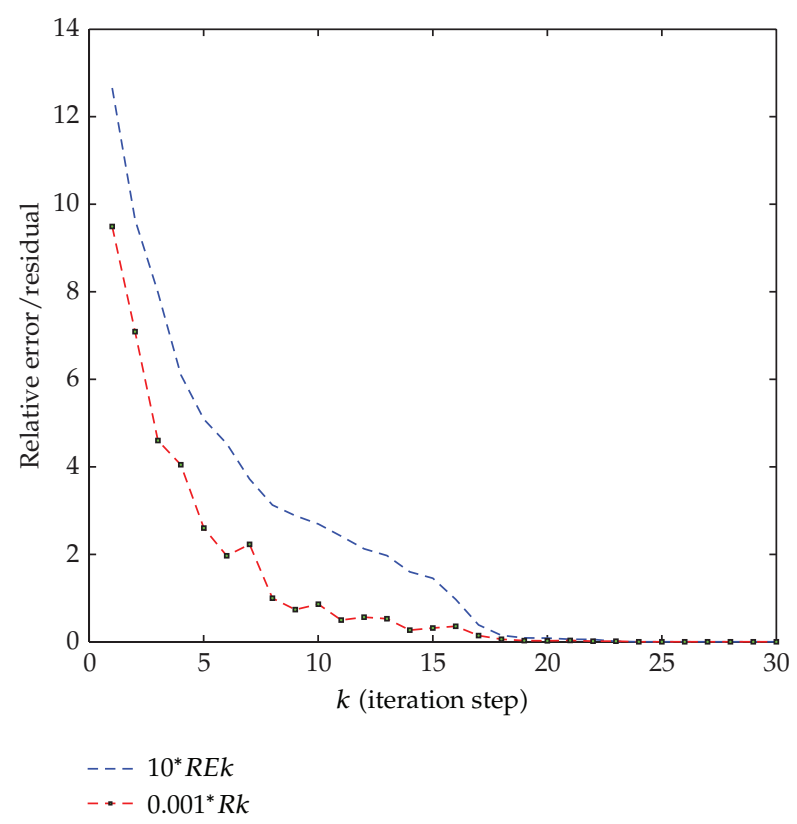

Figure 2: The relative error of the solutions and the residual for Example 4.1 with $X_{1}=0, Y_{1}=0$.

Example 4.3. Let $S_{E}$ denote the set of all generalized reflexive solutions of the matrix equations in Example 4.1. For a given generalized reflexive matrices

$$
X_{0}=\left(\begin{array}{cccc}
3 & -1 & 2 & 2 \\
3 & -2 & 0 & 0 \\
1 & -3 & -1 & -3 \\
0 & 0 & 3 & 2 \\
-2 & 2 & -3 & -1
\end{array}\right), \quad Y_{0}=\left(\begin{array}{ccccc}
2 & 4 & -2 & 2 & 0 \\
1 & 3 & 0 & 1 & 3 \\
5 & -2 & 2 & -5 & 2 \\
2 & 0 & 2 & 2 & 4
\end{array}\right)
$$

we will find $[\widehat{X}, \widehat{Y}] \in S_{E}$, such that

$$
\left\|\widehat{X}-X_{0}\right\|+\left\|\widehat{Y}-Y_{0}\right\|=\min _{[X, Y] \in S_{E}}\left\|X-X_{0}\right\|+\left\|Y-Y_{0}\right\|
$$

that is, find the optimal approximate generalized reflexive solution pair to the matrix pair $\left[X_{0}, Y_{0}\right]$ in $S_{E}$ in Frobenius norm.

Let $\tilde{X}=X-X_{0}, \widetilde{Y}=Y-Y_{0}, \widetilde{M}=M-A X_{0} B+C Y_{0} D, \widetilde{N}=N-E X_{0} F+G Y_{0} H$, by the method mentioned in Section 3, we can obtain the least-norm generalized reflexive solution 
pair $\left[\tilde{X}^{*}, \tilde{Y}^{*}\right]$ of the matrix equations $A \tilde{X} B+C \tilde{Y} D=\widetilde{M}, E \tilde{X} F+G \tilde{Y} H=\widetilde{N}$ by choosing the initial iteration matrices $\tilde{X}_{1}=0$ and $\widetilde{Y}_{1}=0$, then by Algorithm 2.1, we have that

$$
\begin{gathered}
\tilde{X}^{*}=\tilde{X}_{30}^{*}=\left(\begin{array}{ccccc}
-5.0000 & 10.0000 & 0.0000 & 3.0000 \\
-0.0000 & 3.0000 & 11.0000 & -1.0000 \\
6.0000 & 6.0000 & -6.0000 & 6.0000 \\
11.0000 & 1.0000 & -0.0000 & -3.0000 \\
-0.0000 & 3.0000 & 5.0000 & 10.0000
\end{array}\right), \\
\tilde{Y}^{*}=\tilde{Y}_{30}^{*}=\left(\begin{array}{ccccc}
12.0000 & 12.0000 & 1.0000 & 1.0000 & 4.0000 \\
8.0000 & 4.0000 & 0 & 8.0000 & 4.0000 \\
-8.0000 & -6.0000 & -10.0000 & 8.0000 & 6.0000 \\
1.0000 & 4.0000 & -1.0000 & 12.0000 & 12.0000
\end{array}\right), \\
\left\|R_{30}\right\|=6.3482 e-010<\varepsilon=1.0000 e-010
\end{gathered}
$$

and the optimal approximate generalized reflexive solutions to the matrix pair $\left[X_{0}, Y_{0}\right]$ in Frobenius norm are

$$
\begin{gathered}
\hat{X}=\tilde{X}_{30}^{*}+X_{0}=\left(\begin{array}{cccc}
-2.0000 & 9.0000 & 2.0000 & 5.0000 \\
3.0000 & 1.0000 & 11.0000 & -1.0000 \\
7.0000 & 3.0000 & -7.0000 & 3.0000 \\
11.0000 & 1.0000 & 3.0000 & -1.0000 \\
-2.0000 & 5.0000 & 2.0000 & 9.0000
\end{array}\right), \\
\widehat{Y}=\tilde{Y}_{30}^{*}+Y_{0}=\left(\begin{array}{ccccc}
14.0000 & 16.0000 & -1.0000 & 3.0000 & 4.0000 \\
9.0000 & 7.0000 & 0 & 9.0000 & 7.0000 \\
-3.0000 & -8.0000 & -8.0000 & 3.0000 & 8.0000 \\
3.0000 & 4.0000 & 1.0000 & 14.0000 & 16.0000
\end{array}\right) .
\end{gathered}
$$

The relative error of the solutions and the residual are shown in Figure 4, where the relative error $R E k=\left(\left\|\tilde{X}_{k}+X_{0}-X^{*}\right\|+\left\|\tilde{Y}_{k}+Y_{0}-Y^{*}\right\|\right) /\left(\left\|X^{*}\right\|+\left\|Y^{*}\right\|\right)$ and the residual $R k=\left\|R_{k}\right\|$.

\section{Conclusions}

In this paper, an efficient iterative algorithm is presented to solve the generalized coupled Sylvester matrix equations $A X B-C Y D=M, E X Y-G Y H=N$ over generalized reflexive matrix pair $[X, Y] \in \mathcal{R}_{r}^{m \times n}(P, Q) \times \mathcal{R}_{r}^{s \times t}(R, S)$. When the matrix equations $A X B-C Y D=$ $M, E X Y-G Y H=N$ are consistent over generalized reflexive matrices $X$ and $Y$, for any generalized reflexive initial iterative matrix pair $\left[X_{1}, Y_{1}\right] \in \mathcal{R}_{r}^{m \times n}(P, Q) \times \mathcal{R}_{r}^{s \times t}(R, S)$, the generalized reflexive solutions can be obtained by the iterative algorithm within finite 


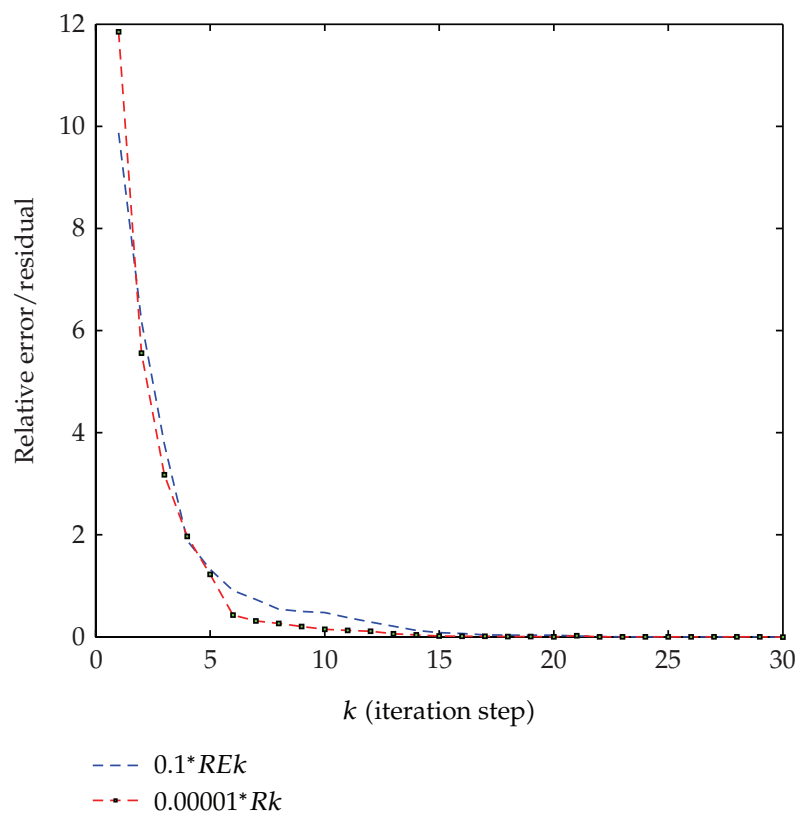

Figure 3: The relative error of the solutions and the residual for Example 4.2.

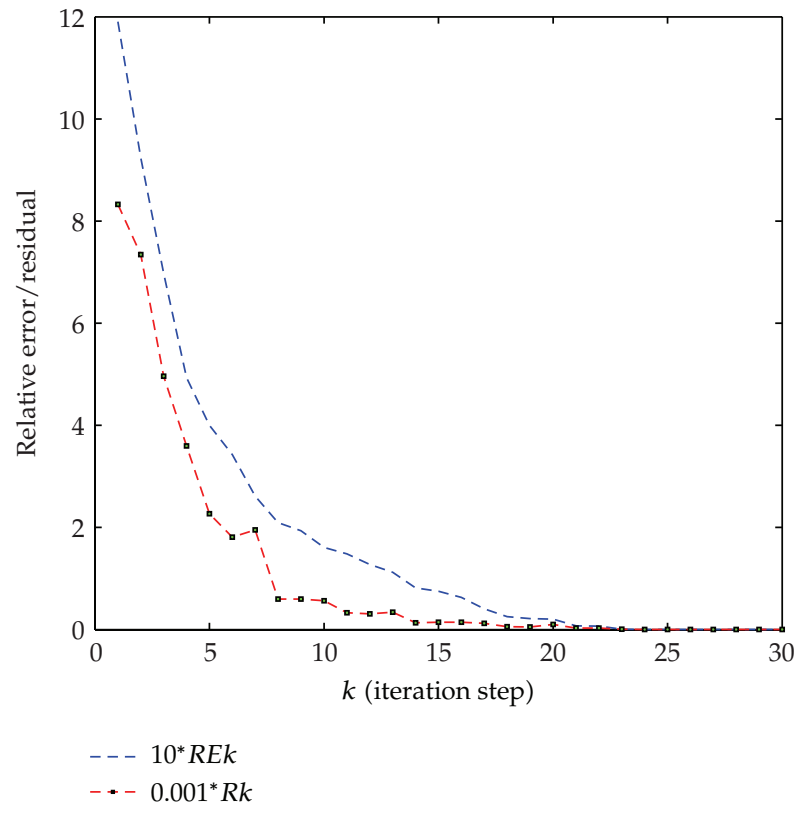

Figure 4: The relative error of the solutions and the residual for Example 4.3.

iterative steps in the absence of round-off errors. Let initial matrices $X_{1}=A^{T} K B^{T}+E^{T} L F^{T}+$ $P A^{T} K B^{T} Q+P E^{T} L F^{T} Q$ and $Y_{1}=-C^{T} K D^{T}-G^{T} L H^{T}-R C^{T} K D^{T} S-R G^{T} L H^{T} S$, where $K \in \mathcal{R}^{p \times q}, L \in R^{k \times l}$ are arbitrary matrices, especially, let $X_{1}=0 \in \mathcal{R}_{r}^{m \times n}(P, Q)$ and $Y_{1}=0 \in \mathcal{R}_{r}^{s \times t}(R, S)$, the unique least-norm generalized reflexive solutions of the matrix 
equations can be derived. Furthermore, the optimal approximate solutions of $A X B-C Y D=$ $M, E X Y-G Y H=N$ for a given generalized reflexive matrix pair $\left[X_{0}, Y_{0}\right] \in \mathcal{R}_{r}^{m \times n}(P, Q) \times$ $\mathcal{R}_{r}^{s \times t}(R, S)$ can be derived by finding the least-norm generalized reflexive solutions of two new corresponding generalized coupled Sylvester matrix equations. Finally, several numerical examples are given to illustrate that our iterative algorithm is quite effective.

The results presented in this paper generalize some previous results $[7,12,13,30]$. When $B=I, C=I, F=I, G=I, P=Q$, and $R=S$, then our results reduce to those in [7]. When $P=Q, R=S, X^{T}=X$, and $Y^{T}=Y$, the results in this paper reduce to those in [12]. When $B=I, C=I, F=I$, and $G=I$, then the results in this paper reduce to those in [13]. When $P=Q$ and $R=S$, then the results in this paper reduce to those in [30].

\section{Appendices}

\section{A. The Proof of Lemma 2.2}

Since $\operatorname{tr}\left(R_{i}^{T} R_{j}\right)=\operatorname{tr}\left(R_{j}^{T} R_{i}\right), \operatorname{tr}\left(U_{i}^{T} U_{j}\right)=\operatorname{tr}\left(U_{j}^{T} U_{i}\right)$, and $\operatorname{tr}\left(V_{i}^{T} V_{j}\right)=\operatorname{tr}\left(V_{j}^{T} V_{i}\right)$ for all $i, j=$ $1,2, \ldots, s$, we only need to prove that

$$
\operatorname{tr}\left(R_{i}^{T} R_{j}\right)=0, \quad \operatorname{tr}\left(U_{i}^{T} U_{j}+V_{i}^{T} V_{j}\right)=0, \quad 1 \leq j<i \leq s .
$$

We prove the conclusion by induction, and two steps are required.

Step 1. We will show that

$$
\operatorname{tr}\left(R_{i+1}^{T} R_{i}\right)=0, \quad \operatorname{tr}\left(U_{i+1}^{T} U_{i}+V_{i+1}^{T} V_{i}\right)=0, \quad i=1,2, \ldots, s-1
$$

To prove this conclusion, we also use induction.

For $i=1$, by Algorithm 2.1, we have that

$$
\begin{aligned}
& \operatorname{tr}\left(R_{2}^{T} R_{1}\right) \\
& =\operatorname{tr}\left(\left[R_{1}-\frac{\left\|R_{1}\right\|^{2}}{\left\|U_{1}\right\|^{2}+\left\|V_{1}\right\|^{2}} \operatorname{diag}\left(\Phi\left(U_{1}, V_{1}\right), \Psi\left(U_{1}, V_{1}\right)\right)\right]^{T} R_{1}\right) \\
& =\left\|R_{1}\right\|^{2}-\frac{\left\|R_{1}\right\|^{2}}{\left\|U_{1}\right\|^{2}+\left\|V_{1}\right\|^{2}} \operatorname{tr}\left(\left(\operatorname{diag}\left(\Phi\left(U_{1}, V_{1}\right), \Psi\left(U_{1}, V_{1}\right)\right)\right)^{T}\right. \\
& \left.=\| \operatorname{diag}\left(M-\Phi\left(X_{1}, Y_{1}\right), N-\Psi\left(X_{1}, Y_{1}\right)\right)\right) \\
& \quad \times \operatorname{tr}\left(\left(\Phi \left(R_{1} \|^{2}-\frac{\left.\left.\left.\left\|R_{1}\right\|^{2}\right)\right)^{T}\left(M-\Phi\left(X_{1}, Y_{1}\right)\right)+\left(\Psi\left(U_{1}, V_{1}\right)\right)^{T}\left(N-\Psi\left(X_{1}, Y_{1}\right)\right)\right)}{\left\|U_{1}+\right\| V_{1} \|^{2}}\right.\right.\right. \\
& =\left\|R_{1}\right\|^{2}-\frac{\left\|R_{1}\right\|^{2}}{\left\|U_{1}\right\|^{2}+\left\|V_{1}\right\|^{2}} \operatorname{tr}\left(U_{1}^{T} A^{T}\left(M-\Phi\left(X_{1}, Y_{1}\right)\right) B^{T}+U_{1}^{T} E^{T}\left(N-\Psi\left(X_{1}, Y_{1}\right)\right) F^{T}\right. \\
& \left.\quad-V_{1}^{T} C^{T}\left(M-\Phi\left(X_{1}, Y_{1}\right)\right) D^{T}-V_{1}^{T} G^{T}\left(N-\Psi\left(X_{1}, Y_{1}\right)\right) H^{T}\right)
\end{aligned}
$$


Journal of Applied Mathematics

$$
\begin{aligned}
& =\left\|R_{1}\right\|^{2}-\frac{\left\|R_{1}\right\|^{2}}{\left\|U_{1}\right\|^{2}+\left\|V_{1}\right\|^{2}} \\
& \times \operatorname{tr}\left(U _ { 1 } ^ { T } \left[\frac{A^{T}\left(M-\Phi\left(X_{1}, Y_{1}\right)\right) B^{T}+E^{T}\left(N-\Psi\left(X_{1}, Y_{1}\right)\right) F^{T}}{2}\right.\right. \\
& +\frac{A^{T}\left(M-\Phi\left(X_{1}, Y_{1}\right)\right) B^{T}+E^{T}\left(N-\Psi\left(X_{1}, Y_{1}\right)\right) F^{T}}{2} \\
& +\frac{P A^{T}\left(M-\Phi\left(X_{1}, Y_{1}\right)\right) B^{T} Q+P E^{T}\left(N-\Psi\left(X_{1}, Y_{1}\right)\right) F^{T} Q}{2} \\
& \left.-\frac{P A^{T}\left(M-\Phi\left(X_{1}, Y_{1}\right)\right) B^{T} Q+P E^{T}\left(N-\Psi\left(X_{1}, Y_{1}\right)\right) F^{T} Q}{2}\right] \\
& +V_{1}^{T}\left[\frac{-C^{T}\left(M-\Phi\left(X_{1}, Y_{1}\right)\right) D^{T}-G^{T}\left(N-\Psi\left(X_{1}, Y_{1}\right)\right) H^{T}}{2}\right. \\
& +\frac{-C^{T}\left(M-\Phi\left(X_{1}, Y_{1}\right)\right) D^{T}-G^{T}\left(N-\Psi\left(X_{1}, Y_{1}\right)\right) H^{T}}{2} \\
& +\frac{-R C^{T}\left(M-\Phi\left(X_{1}, Y_{1}\right)\right) D^{T} S-R G^{T}\left(N-\Psi\left(X_{1}, Y_{1}\right)\right) H^{T} S}{2} \\
& \left.\left.-\frac{-R C^{T}\left(M-\Phi\left(X_{1}, Y_{1}\right)\right) D^{T} S-R G^{T}\left(N-\Psi\left(X_{1}, Y_{1}\right)\right) H^{T} S}{2}\right]\right) \\
& =\left\|R_{1}\right\|^{2}-\frac{\left\|R_{1}\right\|^{2}}{\left\|U_{1}\right\|^{2}+\left\|V_{1}\right\|^{2}} \\
& \times \operatorname{tr}\left(U _ { 1 } ^ { T } \left[\frac{A^{T}\left(M-\Phi\left(X_{1}, Y_{1}\right)\right) B^{T}+E^{T}\left(N-\Psi\left(X_{1}, Y_{1}\right)\right) F^{T}}{2}\right.\right. \\
& \left.+\frac{P A^{T}\left(M-\Phi\left(X_{1}, Y_{1}\right)\right) B^{T} Q+P E^{T}\left(N-\Psi\left(X_{1}, Y_{1}\right)\right) F^{T} Q}{2}\right] \\
& +V_{1}^{T}\left[\frac{-C^{T}\left(M-\Phi\left(X_{1}, Y_{1}\right)\right) D^{T}-G^{T}\left(N-\Psi\left(X_{1}, Y_{1}\right)\right) H^{T}}{2}\right. \\
& \left.\left.+\frac{-R C^{T}\left(M-\Phi\left(X_{1}, Y_{1}\right)\right) D^{T} S-R G^{T}\left(N-\Psi\left(X_{1}, Y_{1}\right)\right) H^{T} S}{2}\right]\right) \\
& =\left\|R_{1}\right\|^{2}-\frac{\left\|R_{1}\right\|^{2}}{\left\|U_{1}\right\|^{2}+\left\|V_{1}\right\|^{2}} \operatorname{tr}\left(U_{1}^{T} U_{1}+V_{1}^{T} V_{1}\right)=0, \\
& \operatorname{tr}\left(U_{2}^{T} U_{1}\right)+\operatorname{tr}\left(V_{2}^{T} V_{1}\right) \\
& =\operatorname{tr}\left(\left[\frac{A^{T}\left(M-\Phi\left(X_{2}, Y_{2}\right)\right) B^{T}+E^{T}\left(N-\Psi\left(X_{2}, Y_{2}\right)\right) F^{T}}{2}\right.\right. \\
& \left.\left.+\frac{P A^{T}\left(M-\Phi\left(X_{2}, Y_{2}\right)\right) B^{T} Q+P E^{T}\left(N-\Psi\left(X_{2}, Y_{2}\right)\right) F^{T} Q}{2}+\frac{\left\|R_{2}\right\|^{2}}{\left\|R_{1}\right\|^{2}} U_{1}\right]^{T} U_{1}\right)
\end{aligned}
$$




$$
\begin{aligned}
& +\operatorname{tr}\left(\left[\frac{-C^{T}\left(M-\Phi\left(X_{2}, Y_{2}\right)\right) D^{T}-G^{T}\left(N-\Psi\left(X_{2}, Y_{2}\right)\right) H^{T}}{2}\right.\right. \\
& \left.\left.+\frac{-R C^{T}\left(M-\Phi\left(X_{2}, Y_{2}\right)\right) D^{T} S-R G^{T}\left(N-\Psi\left(X_{2}, Y_{2}\right)\right) H^{T} S}{2}+\frac{\left\|R_{2}\right\|^{2}}{\left\|R_{1}\right\|^{2}} V_{1}\right]^{T} V_{1}\right) \\
= & \operatorname{tr}\left(\left[A^{T}\left(M-\Phi\left(X_{2}, Y_{2}\right)\right) B^{T}+E^{T}\left(N-\Psi\left(X_{2}, Y_{2}\right)\right) F^{T}+\frac{\left\|R_{2}\right\|^{2}}{\left\|R_{1}\right\|^{2}} U_{1}\right]^{T} U_{1}\right) \\
& +\operatorname{tr}\left(\left[-C^{T}\left(M-\Phi\left(X_{2}, Y_{2}\right)\right) D^{T}-G^{T}\left(N-\Psi\left(X_{2}, Y_{2}\right)\right) H^{T}+\frac{\left\|R_{2}\right\|^{2}}{\left\|R_{1}\right\|^{2}} V_{1}\right]^{T} V_{1}\right) \\
= & \operatorname{tr}\left(U_{1}^{T}\left[A^{T}\left(M-\Phi\left(X_{2}, Y_{2}\right)\right) B^{T}+E^{T}\left(N-\Psi\left(X_{2}, Y_{2}\right)\right) F^{T}\right]\right. \\
& \left.+V_{1}^{T}\left[-C^{T}\left(M-\Phi\left(X_{2}, Y_{2}\right)\right) D^{T}-G^{T}\left(N-\Psi\left(X_{2}, Y_{2}\right)\right) H^{T}\right]\right)+\frac{\left\|R_{2}\right\|^{2}}{\left\|R_{1}\right\|^{2}}\left(\left\|U_{1}\right\|^{2}+\left\|V_{1}\right\|^{2}\right) \\
= & \operatorname{tr}\left(\left(M-\Phi\left(X_{2}, Y_{2}\right)\right)^{T} A U_{1} B+\left(N-\Psi\left(X_{2}, Y_{2}\right)\right)^{T} E U_{1} F-\left(M-\Phi\left(X_{2}, Y_{2}\right)\right)^{T} C V_{1} D\right. \\
& \left.-\left(N-\Psi\left(X_{2}, Y_{2}\right)\right)^{T} G V_{1} H\right)+\frac{\left\|R_{2}\right\|^{2}}{\left\|R_{1}\right\|^{2}}\left(\left\|U_{1}\right\|^{2}+\left\|V_{1}\right\|^{2}\right) \\
= & \operatorname{tr}\left(\operatorname{diag}\left(\left(M-\Phi\left(X_{2}, Y_{2}\right)\right)^{T},\left(N-\Psi\left(X_{2}, Y_{2}\right)\right)^{T}\right) \operatorname{diag}\left(\Phi\left(U_{1}, V_{1}\right), \Psi\left(U_{1}, V_{1}\right)\right)\right) \\
& +\frac{\left\|R_{2}\right\|^{2}}{\left\|R_{1}\right\|^{2}\left(\left\|U_{1}\right\|^{2}+\left\|V_{1}\right\|^{2}\right)}\left\|R_{1}\right\|^{2} \|^{2} \operatorname{tr}\left(R_{2}^{T}\left(R_{1}-R_{2}\right)\right)+\frac{\left\|R_{2}\right\|^{2}}{\left\|R_{1}\right\|^{2}}\left(\left\|U_{1}\right\|^{2}+\left\|V_{1}\right\|^{2}\right)=0 . \\
& =(M)
\end{aligned}
$$

Assume that (A.2) holds for $i=k-1$, that is, $\operatorname{tr}\left(R_{k}^{T} R_{k-1}\right)=0, \operatorname{tr}\left(U_{k}^{T} U_{k-1}+V_{k}^{T} V_{k-1}\right)=0$. When $i=k$, we have that

$$
\begin{aligned}
& \operatorname{tr}\left(R_{k+1}^{T} R_{k}\right) \\
& =\operatorname{tr}\left(\left[R_{k}-\frac{\left\|R_{k}\right\|^{2}}{\left\|U_{k}\right\|^{2}+\left\|V_{k}\right\|^{2}} \operatorname{diag}\left(\Phi\left(U_{k}, V_{k}\right), \Psi\left(U_{k}, V_{k}\right)\right)\right]^{T} R_{k}\right) \\
& =\left\|R_{k}\right\|^{2}-\frac{\left\|R_{k}\right\|^{2}}{\left\|U_{k}\right\|^{2}+\left\|V_{k}\right\|^{2}} \operatorname{tr}\left(\operatorname{diag}\left(\Phi\left(U_{k}, V_{k}\right), \Psi\left(U_{k}, V_{k}\right)\right)\right)^{T} \\
& \quad \times \operatorname{diag}\left(M-\Phi\left(X_{k}, Y_{k}\right), N-\Psi\left(X_{k}, Y_{k}\right)\right)
\end{aligned}
$$


Journal of Applied Mathematics

$$
\begin{aligned}
& =\left\|R_{k}\right\|^{2}-\frac{\left\|R_{k}\right\|^{2}}{\left\|U_{k}\right\|^{2}+\left\|V_{k}\right\|^{2}} \\
& \times \operatorname{tr}\left(\left(\Phi\left(U_{k}, V_{k}\right)\right)^{T}\left(M-\Phi\left(X_{k}, Y_{k}\right)\right)+\left(\Psi\left(U_{k}, V_{k}\right)\right)^{T}\left(N-\Psi\left(X_{k}, Y_{k}\right)\right)\right) \\
& =\left\|R_{k}\right\|^{2}-\frac{\left\|R_{k}\right\|^{2}}{\left\|U_{k}\right\|^{2}+\left\|V_{k}\right\|^{2}} \operatorname{tr}\left(U_{k}^{T} A^{T}\left(M-\Phi\left(X_{k}, Y_{k}\right)\right) B^{T}+U_{k}^{T} E^{T}\left(N-\Psi\left(X_{k}, Y_{k}\right)\right) F^{T}\right. \\
& \left.-V_{k}^{T} C^{T}\left(M-\Phi\left(X_{k}, Y_{k}\right)\right) D^{T}-V_{k}^{T} G^{T}\left(N-\Psi\left(X_{k}, Y_{k}\right)\right) H^{T}\right) \\
& =\left\|R_{k}\right\|^{2}-\frac{\left\|R_{k}\right\|^{2}}{\left\|U_{k}\right\|^{2}+\left\|V_{k}\right\|^{2}} \operatorname{tr}\left(U _ { k } ^ { T } \left[\frac{A^{T}\left(M-\Phi\left(X_{k}, Y_{k}\right)\right) B^{T}+E^{T}\left(N-\Psi\left(X_{k}, Y_{k}\right)\right) F^{T}}{2}\right.\right. \\
& +\frac{A^{T}\left(M-\Phi\left(X_{k}, Y_{k}\right)\right) B^{T}+E^{T}\left(N-\Psi\left(X_{k}, Y_{k}\right)\right) F^{T}}{2} \\
& +\frac{P A^{T}\left(M-\Phi\left(X_{k}, Y_{k}\right)\right) B^{T} Q+P E^{T}\left(N-\Psi\left(X_{k}, Y_{k}\right)\right) F^{T} Q}{2} \\
& \left.-\frac{P A^{T}\left(M-\Phi\left(X_{k}, Y_{k}\right)\right) B^{T} Q+P E^{T}\left(N-\Psi\left(X_{k}, Y_{k}\right)\right) F^{T} Q}{2}\right] \\
& +V_{k}^{T}\left[\frac{-C^{T}\left(M-\Phi\left(X_{k}, Y_{k}\right)\right) D^{T}-G^{T}\left(N-\Psi\left(X_{k}, Y_{k}\right)\right) H^{T}}{2}\right. \\
& +\frac{-C^{T}\left(M-\Phi\left(X_{k}, Y_{k}\right)\right) D^{T}-G^{T}\left(N-\Psi\left(X_{k}, Y_{k}\right)\right) H^{T}}{2} \\
& +\frac{-R C^{T}\left(M-\Phi\left(X_{k}, Y_{k}\right)\right) D^{T} S-R G^{T}\left(N-\Psi\left(X_{k}, Y_{k}\right)\right) H^{T} S}{2} \\
& \left.\left.-\frac{-R C^{T}\left(M-\Phi\left(X_{k}, Y_{k}\right)\right) D^{T} S-R G^{T}\left(N-\Psi\left(X_{k}, Y_{k}\right)\right) H^{T} S}{2}\right]\right) \\
& =\left\|R_{k}\right\|^{2}-\frac{\left\|R_{k}\right\|^{2}}{\left\|U_{k}\right\|^{2}+\left\|V_{k}\right\|^{2}} \operatorname{tr}\left(U _ { k } ^ { T } \left[\frac{A^{T}\left(M-\Phi\left(X_{k}, Y_{k}\right)\right) B^{T}+E^{T}\left(N-\Psi\left(X_{k}, Y_{k}\right)\right) F^{T}}{2}\right.\right. \\
& \left.+\frac{P A^{T}\left(M-\Phi\left(X_{k}, Y_{k}\right)\right) B^{T} Q+P E^{T}\left(N-\Psi\left(X_{k}, Y_{k}\right)\right) F^{T} Q}{2}\right] \\
& +V_{k}^{T}\left[\frac{-C^{T}\left(M-\Phi\left(X_{k}, Y_{k}\right)\right) D^{T}-G^{T}\left(N-\Psi\left(X_{k}, Y_{k}\right)\right) H^{T}}{2}\right. \\
& \left.\left.+\frac{-R C^{T}\left(M-\Phi\left(X_{k}, Y_{k}\right)\right) D^{T} S-R G^{T}\left(N-\Psi\left(X_{k}, Y_{k}\right)\right) H^{T} S}{2}\right]\right) \\
& =\left\|R_{k}\right\|^{2}-\frac{\left\|R_{k}\right\|^{2}}{\left\|U_{k}\right\|^{2}+\left\|V_{k}\right\|^{2}} \operatorname{tr}\left(U_{k}^{T} U_{k}+V_{k}^{T} V_{k}\right)=0, \\
& \operatorname{tr}\left(U_{k+1}^{T} U_{k}\right)+\operatorname{tr}\left(V_{k+1}^{T} V_{k}\right)
\end{aligned}
$$




$$
\begin{aligned}
& =\operatorname{tr}\left(\left[\frac{A^{T}\left(M-\Phi\left(X_{k+1}, Y_{k+1}\right)\right) B^{T}+E^{T}\left(N-\Psi\left(X_{k+1}, Y_{k+1}\right)\right) F^{T}}{2}\right.\right. \\
& +\frac{P A^{T}\left(M-\Phi\left(X_{k+1}, Y_{k+1}\right)\right) B^{T} Q+P E^{T}\left(N-\Psi\left(X_{k+1}, Y_{k+1}\right)\right) F^{T} Q}{2} \\
& \left.\left.+\frac{\left\|R_{k+1}\right\|^{2}}{\left\|R_{k}\right\|^{2}} U_{k}\right]^{T} U_{k}\right) \\
& +\operatorname{tr}\left(\left[\frac{-C^{T}\left(M-\Phi\left(X_{k+1}, Y_{k+1}\right)\right) D^{T}-G^{T}\left(N-\Psi\left(X_{k+1}, Y_{k+1}\right)\right) H^{T}}{2}\right.\right. \\
& +\frac{-R C^{T}\left(M-\Phi\left(X_{k+1}, Y_{k+1}\right)\right) D^{T} S-R G^{T}\left(N-\Psi\left(X_{k+1}, Y_{k+1}\right)\right) H^{T} S}{2} \\
& \left.\left.+\frac{\left\|R_{k+1}\right\|^{2}}{\left\|R_{k}\right\|^{2}} V_{k}\right]^{T} V_{k}\right) \\
& =\operatorname{tr}\left(\left[A^{T}\left(M-\Phi\left(X_{k+1}, Y_{k+1}\right)\right) B^{T}+E^{T}\left(N-\Psi\left(X_{k+1}, Y_{k+1}\right)\right) F^{T}+\frac{\left\|R_{k+1}\right\|^{2}}{\left\|R_{k}\right\|^{2}} U_{k}\right]^{T} U_{k}\right) \\
& +\operatorname{tr}\left(\left[-C^{T}\left(M-\Phi\left(X_{k+1}, Y_{k+1}\right)\right) D^{T}-G^{T}\left(N-\Psi\left(X_{k+1}, Y_{k+1}\right)\right) H^{T}+\frac{\left\|R_{k+1}\right\|^{2}}{\left\|R_{k}\right\|^{2}} V_{k}\right]^{T} V_{k}\right) \\
& =\operatorname{tr}\left(U_{k}^{T}\left[A^{T}\left(M-\Phi\left(X_{k+1}, Y_{k+1}\right)\right) B^{T}+E^{T}\left(N-\Psi\left(X_{k+1}, Y_{k+1}\right)\right) F^{T}\right]\right. \\
& \left.+V_{k}^{T}\left[-C^{T}\left(M-\Phi\left(X_{k+1}, Y_{k+1}\right)\right) D^{T}-G^{T}\left(N-\Psi\left(X_{k+1}, Y_{k+1}\right)\right) H^{T}\right]\right) \\
& +\frac{\left\|R_{k+1}\right\|^{2}}{\left\|R_{k}\right\|^{2}}\left(\left\|U_{k}\right\|^{2}+\left\|V_{k}\right\|^{2}\right) \\
& =\operatorname{tr}\left(\left(M-\Phi\left(X_{k+1}, Y_{k+1}\right)\right)^{T} A U_{k} B+\left(N-\Psi\left(X_{k+1}, Y_{k+1}\right)\right)^{T} E U_{k} F\right. \\
& -\left(M-\Phi\left(X_{k+1}, Y_{k+1}\right)\right)^{T} C V_{k} D \\
& \left.-\left(N-\Psi\left(X_{k+1}, Y_{k+1}\right)\right)^{T} G V_{k} H\right)+\frac{\left\|R_{k+1}\right\|^{2}}{\left\|R_{k}\right\|^{2}}\left(\left\|U_{k}\right\|^{2}+\left\|V_{k}\right\|^{2}\right) \\
& =\operatorname{tr}\left(\operatorname{diag}\left(\left(M-\Phi\left(X_{k+1}, Y_{k+1}\right)\right)^{T},\left(N-\Psi\left(X_{k+1}, Y_{k+1}\right)\right)^{T}\right) \operatorname{diag}\left(\Phi\left(U_{k}, V_{k}\right), \Psi\left(U_{k}, V_{k}\right)\right)\right) \\
& +\frac{\left\|R_{k+1}\right\|^{2}}{\left\|R_{k}\right\|^{2}}\left(\left\|U_{k}\right\|^{2}+\left\|V_{k}\right\|^{2}\right) \\
& =\frac{\left\|U_{k}\right\|^{2}+\left\|V_{k}\right\|^{2}}{\left\|R_{k}\right\|^{2}} \operatorname{tr}\left(R_{k+1}^{T}\left(R_{k}-R_{k+1}\right)\right)+\frac{\left\|R_{k+1}\right\|^{2}}{\left\|R_{k}\right\|^{2}}\left(\left\|U_{k}\right\|^{2}+\left\|V_{k}\right\|^{2}\right)=0 .
\end{aligned}
$$

Hence, (A.2) holds for $i=k$. Therefore, (A.2) holds by the principle of induction. 
Journal of Applied Mathematics

Step 2. We show that

$$
\operatorname{tr}\left(R_{i+1}^{T} R_{j}\right)=0, \quad \operatorname{tr}\left(U_{i+1}^{T} U_{j}+V_{i+1}^{T} V_{j}\right)=0, \quad j=1,2, \ldots, i, \forall i \geq 1
$$

When $i=1$, (A.5) holds.

Assume that

$$
\operatorname{tr}\left(R_{i}^{T} R_{j}\right)=0, \quad \operatorname{tr}\left(U_{i}^{T} U_{j}+V_{i}^{T} V_{j}\right)=0, \quad j=1,2, \ldots, s-1, \forall s \geq 2,
$$

then we show that

$$
\operatorname{tr}\left(R_{i+1}^{T} R_{j}\right)=0, \quad \operatorname{tr}\left(U_{i+1}^{T} U_{j}+V_{i+1}^{T} V_{j}\right)=0, \quad j=1,2, \ldots, s .
$$

In fact, we have that

$$
\begin{aligned}
& \operatorname{tr}\left(R_{i+1}^{T} R_{j}\right) \\
& =\operatorname{tr}\left(\left[R_{i}-\frac{\left\|R_{i}\right\|^{2}}{\left\|U_{i}\right\|^{2}+\left\|V_{i}\right\|^{2}} \operatorname{diag}\left(\Phi\left(U_{i}, V_{i}\right), \Psi\left(U_{i}, V_{i}\right)\right)\right]^{T} R_{j}\right) \\
& =\operatorname{tr}\left(R_{i}^{T} R_{j}\right)-\frac{\left\|R_{i}\right\|^{2}}{\left\|U_{i}\right\|^{2}+\left\|V_{i}\right\|^{2}} \operatorname{tr}\left(\operatorname{diag}\left(\Phi\left(U_{i}, V_{i}\right), \Psi\left(U_{i}, V_{i}\right)\right)\right)^{T} \\
& \times \operatorname{diag}\left(M-\Phi\left(X_{j}, Y_{j}\right), N-\Psi\left(X_{j}, Y_{j}\right)\right) \\
& =-\frac{\left\|R_{i}\right\|^{2}}{\left\|U_{i}\right\|^{2}+\left\|V_{i}\right\|^{2}} \operatorname{tr}\left(\left(\Phi\left(U_{i}, V_{i}\right)\right)^{T}\left(M-\Phi\left(X_{j}, Y_{j}\right)\right)+\left(\Psi\left(U_{i}, V_{i}\right)\right)^{T}\left(N-\Psi\left(X_{j}, Y_{j}\right)\right)\right) \\
& =-\frac{\left\|R_{i}\right\|^{2}}{\left\|U_{i}\right\|^{2}+\left\|V_{i}\right\|^{2}} \operatorname{tr}\left(U_{i}^{T} A^{T}\left(M-\Phi\left(X_{j}, Y_{j}\right)\right) B^{T}+U_{i}^{T} E^{T}\left(N-\Psi\left(X_{j}, Y_{j}\right)\right) F^{T}\right. \\
& \left.-V_{i}^{T} C^{T}\left(M-\Phi\left(X_{j}, Y_{j}\right)\right) D^{T}-V_{i}^{T} G^{T}\left(N-\Psi\left(X_{j}, Y_{j}\right)\right) H^{T}\right) \\
& =-\frac{\left\|R_{i}\right\|^{2}}{\left\|U_{i}\right\|^{2}+\left\|V_{i}\right\|^{2}} \operatorname{tr}\left(U _ { i } ^ { T } \left[\frac{A^{T}\left(M-\Phi\left(X_{j}, Y_{j}\right)\right) B^{T}+E^{T}\left(N-\Psi\left(X_{j}, Y_{j}\right)\right) F^{T}}{2}\right.\right. \\
& +\frac{A^{T}\left(M-\Phi\left(X_{j}, Y_{j}\right)\right) B^{T}+E^{T}\left(N-\Psi\left(X_{j}, Y_{j}\right)\right) F^{T}}{2} \\
& +\frac{P A^{T}\left(M-\Phi\left(X_{j}, Y_{j}\right)\right) B^{T} Q+P E^{T}\left(N-\Psi\left(X_{j}, Y_{j}\right)\right) F^{T} Q}{2} \\
& \left.-\frac{P A^{T}\left(M-\Phi\left(X_{j}, Y_{j}\right)\right) B^{T} Q+P E^{T}\left(N-\Psi\left(X_{j}, Y_{j}\right)\right) F^{T} Q}{2}\right]
\end{aligned}
$$




$$
\begin{aligned}
& +V_{i}^{T}\left[\frac{-C^{T}\left(M-\Phi\left(X_{j}, Y_{j}\right)\right) D^{T}-G^{T}\left(N-\Psi\left(X_{j}, Y_{j}\right)\right) H^{T}}{2}\right. \\
& +\frac{-C^{T}\left(M-\Phi\left(X_{j}, Y_{j}\right)\right) D^{T}-G^{T}\left(N-\Psi\left(X_{j}, Y_{j}\right)\right) H^{T}}{2} \\
& +\frac{-R C^{T}\left(M-\Phi\left(X_{j}, Y_{j}\right)\right) D^{T} S-R G^{T}\left(N-\Psi\left(X_{j}, Y_{j}\right)\right) H^{T} S}{2} \\
& \left.\left.-\frac{-R C^{T}\left(M-\Phi\left(X_{j}, Y_{j}\right)\right) D^{T} S-R G^{T}\left(N-\Psi\left(X_{j}, Y_{j}\right)\right) H^{T} S}{2}\right]\right) \\
& =-\frac{\left\|R_{i}\right\|^{2}}{\left\|U_{i}\right\|^{2}+\left\|V_{i}\right\|^{2}} \operatorname{tr}\left(U _ { i } ^ { T } \left[\frac{A^{T}\left(M-\Phi\left(X_{j}, Y_{j}\right)\right) B^{T}+E^{T}\left(N-\Psi\left(X_{j}, Y_{j}\right)\right) F^{T}}{2}\right.\right. \\
& \left.+\frac{P A^{T}\left(M-\Phi\left(X_{j}, Y_{j}\right)\right) B^{T} Q+P E^{T}\left(N-\Psi\left(X_{j}, Y_{j}\right)\right) F^{T} Q}{2}\right] \\
& +V_{i}^{T}\left[\frac{-C^{T}\left(M-\Phi\left(X_{j}, Y_{j}\right)\right) D^{T}-G^{T}\left(N-\Psi\left(X_{j}, Y_{j}\right)\right) H^{T}}{2}\right. \\
& \left.\left.+\frac{-R C^{T}\left(M-\Phi\left(X_{j}, Y_{j}\right)\right) D^{T} S-R G^{T}\left(N-\Psi\left(X_{j}, Y_{j}\right)\right) H^{T} S}{2}\right]\right) \\
& =-\frac{\left\|R_{i}\right\|^{2}}{\left\|U_{i}\right\|^{2}+\left\|V_{i}\right\|^{2}} \operatorname{tr}\left(U_{i}^{T}\left(U_{j}-\frac{\left\|R_{j}\right\|^{2}}{\left\|R_{j-1}\right\|^{2}} U_{j-1}\right)+V_{i}^{T}\left(V_{j}-\frac{\left\|R_{j}\right\|^{2}}{\left\|R_{j-1}\right\|^{2}} V_{j-1}\right)\right) \\
& =-\frac{\left\|R_{i}\right\|^{2}}{\left\|U_{i}\right\|^{2}+\left\|V_{i}\right\|^{2}} \operatorname{tr}\left(U_{i}^{T} U_{j}+V_{i}^{T} V_{j}\right)+\frac{\left\|R_{i}\right\|^{2}\left\|R_{j}\right\|^{2}}{\left(\left\|U_{i}\right\|^{2}+\left\|V_{i}\right\|^{2}\right)\left\|R_{j-1}\right\|^{4}} \\
& \times\left(\operatorname{tr}\left(U_{i}^{T} U_{j-1}\right)+\operatorname{tr}\left(V_{i}^{T} V_{j-1}\right)\right)=0 .
\end{aligned}
$$

From the above results, we have $\operatorname{tr}\left(R_{i+1}^{T} R_{j+1}\right)=0, j=1,2, \ldots, s-1$, and

$$
\begin{aligned}
\operatorname{tr}\left(U_{i+1}^{T} U_{j}\right)+\operatorname{tr}\left(V_{i+1}^{T} V_{j}\right) \\
=\operatorname{tr}\left(\left[\frac{A^{T}\left(M-\Phi\left(X_{i+1}, Y_{i+1}\right)\right) B^{T}+E^{T}\left(N-\Psi\left(X_{i+1}, Y_{i+1}\right)\right) F^{T}}{2}\right.\right. \\
+\frac{P A^{T}\left(M-\Phi\left(X_{i+1}, Y_{i+1}\right)\right) B^{T} Q+P E^{T}\left(N-\Psi\left(X_{i+1}, Y_{i+1}\right)\right) F^{T} Q}{2} \\
\left.\left.+\frac{\left\|R_{i+1}\right\|^{2}}{\left\|R_{i}\right\|^{2}} U_{i}\right]^{T} U_{j}\right)
\end{aligned}
$$


Journal of Applied Mathematics

$$
\begin{aligned}
& +\operatorname{tr}\left(\left[\frac{-C^{T}\left(M-\Phi\left(X_{i+1}, Y_{i+1}\right)\right) D^{T}-G^{T}\left(N-\Psi\left(X_{i+1}, Y_{i+1}\right)\right) H^{T}}{2}\right.\right. \\
& +\frac{-R C^{T}\left(M-\Phi\left(X_{i+1}, Y_{i+1}\right)\right) D^{T} S-R G^{T}\left(N-\Psi\left(X_{i+1}, Y_{i+1}\right)\right) H^{T} S}{2} \\
& \left.\left.+\frac{\left\|R_{i+1}\right\|^{2}}{\left\|R_{i}\right\|^{2}} V_{i}\right]^{T} V_{j}\right) \\
& =\operatorname{tr}\left(\left[A^{T}\left(M-\Phi\left(X_{i+1}, Y_{i+1}\right)\right) B^{T}+E^{T}\left(N-\Psi\left(X_{i+1}, Y_{i+1}\right)\right) F^{T}+\frac{\left\|R_{i+1}\right\|^{2}}{\left\|R_{i}\right\|^{2}} U_{i}\right]^{T} U_{j}\right) \\
& +\operatorname{tr}\left(\left[-C^{T}\left(M-\Phi\left(X_{i+1}, Y_{i+1}\right)\right) D^{T}-G^{T}\left(N-\Psi\left(X_{i+1}, Y_{i+1}\right)\right) H^{T}+\frac{\left\|R_{i+1}\right\|^{2}}{\left\|R_{i}\right\|^{2}} V_{i}\right]^{T} V_{j}\right) \\
& =\operatorname{tr}\left(U_{j}^{T}\left[A^{T}\left(M-\Phi\left(X_{i+1}, Y_{i+1}\right)\right) B^{T}+E^{T}\left(N-\Psi\left(X_{i+1}, Y_{i+1}\right)\right) F^{T}\right]\right. \\
& \left.+V_{j}^{T}\left[-C^{T}\left(M-\Phi\left(X_{i+1}, Y_{i+1}\right)\right) D^{T}-G^{T}\left(N-\Psi\left(X_{i+1}, Y_{i+1}\right)\right) H^{T}\right]\right) \\
& +\frac{\left\|R_{i+1}\right\|^{2}}{\left\|R_{i}\right\|^{2}}\left[\operatorname{tr}\left(U_{i}^{T} U_{j}\right)+\operatorname{tr}\left(V_{i}^{T} V_{j}\right)\right] \\
& =\operatorname{tr}\left(\left(M-\Phi\left(X_{i+1}, Y_{i+1}\right)\right)^{T} A U_{j} B+\left(N-\Psi\left(X_{i+1}, Y_{i+1}\right)\right)^{T} E U_{j} F\right. \\
& \text { - }\left(M-\Phi\left(X_{i+1}, Y_{i+1}\right)\right)^{T} C V_{j} D \\
& \left.-\left(N-\Psi\left(X_{i+1}, Y_{i+1}\right)\right)^{T} G V_{j} H\right)+\frac{\left\|R_{i+1}\right\|^{2}}{\left\|R_{i}\right\|^{2}}\left[\operatorname{tr}\left(U_{i}^{T} U_{j}\right)+\operatorname{tr}\left(V_{i}^{T} V_{j}\right)\right] \\
& =\operatorname{tr}\left(\operatorname{diag}\left(\left(M-\Phi\left(X_{i+1}, Y_{i+1}\right)\right)^{T},\left(N-\Psi\left(X_{i+1}, Y_{i+1}\right)\right)^{T}\right) \operatorname{diag}\left(\Phi\left(U_{j}, V_{j}\right), \Psi\left(U_{j}, V_{j}\right)\right)\right) \\
& +\frac{\left\|R_{i+1}\right\|^{2}}{\left\|R_{i}\right\|^{2}}\left[\operatorname{tr}\left(U_{i}^{T} U_{j}\right)+\operatorname{tr}\left(V_{i}^{T} V_{j}\right)\right] \\
& =\frac{\left\|U_{j}\right\|^{2}+\left\|V_{j}\right\|^{2}}{\left\|R_{j}\right\|^{2}} \operatorname{tr}\left(R_{i+1}^{T}\left(R_{j}-R_{j+1}\right)\right)+\frac{\left\|R_{i+1}\right\|^{2}}{\left\|R_{i}\right\|^{2}}\left[\operatorname{tr}\left(U_{i}^{T} U_{j}\right)+\operatorname{tr}\left(V_{i}^{T} V_{j}\right)\right]=0 .
\end{aligned}
$$

By the principle of induction, (A.5) holds.

Noting that (A.1) is implied in Steps 1 and 2 by the principle of induction. This completes the proof.

\section{B. The Proof of Lemma 2.3}

We proof the conclusion by induction. 
For $i=1$, we have that

$$
\begin{aligned}
& \operatorname{tr}\left(\left(X^{*}-X_{1}\right)^{T} U_{1}+\left(Y^{*}-Y_{1}\right)^{T} V_{1}\right) \\
& =\operatorname{tr}\left(( X ^ { * } - X _ { 1 } ) ^ { T } \left[\frac{A^{T}\left(M-\Phi\left(X_{1}, Y_{1}\right)\right) B^{T}+E^{T}\left(N-\Psi\left(X_{1}, Y_{1}\right)\right) F^{T}}{2}\right.\right. \\
& \left.+\frac{P A^{T}\left(M-\Phi\left(X_{1}, Y_{1}\right)\right) B^{T} Q+P E^{T}\left(N-\Psi\left(X_{1}, Y_{1}\right)\right) F^{T} Q}{2}\right] \\
& +\left(Y^{*}-Y_{1}\right)^{T}\left[\frac{-C^{T}\left(M-\Phi\left(X_{1}, Y_{1}\right)\right) D^{T}-G^{T}\left(N-\Psi\left(X_{1}, Y_{1}\right)\right) H^{T}}{2}\right. \\
& \left.\left.+\frac{-R C^{T}\left(M-\Phi\left(X_{1}, Y_{1}\right)\right) D^{T} S-R G^{T}\left(N-\Psi\left(X_{1}, Y_{1}\right)\right) H^{T} S}{2}\right]\right) \\
& =\operatorname{tr}\left(\left(X^{*}-X_{1}\right)^{T}\left[A^{T}\left(M-\Phi\left(X_{1}, Y_{1}\right)\right) B^{T}+E^{T}\left(N-\Psi\left(X_{1}, Y_{1}\right)\right) F^{T}\right]\right. \\
& \left.+\left(Y^{*}-Y_{1}\right)^{T}\left[-C^{T}\left(M-\Phi\left(X_{1}, Y_{1}\right)\right) D^{T}-G^{T}\left(N-\Psi\left(X_{1}, Y_{1}\right)\right) H^{T}\right]\right) \\
& =\operatorname{tr}\left(\left(M-\Phi\left(X_{1}, Y_{1}\right)\right)^{T} A\left(X^{*}-X_{1}\right) B+\left(N-\Psi\left(X_{1}, Y_{1}\right)\right)^{T} E\left(X^{*}-X_{1}\right) F\right. \\
& \left.-\left(M-\Phi\left(X_{1}, Y_{1}\right)\right)^{T} C\left(Z^{*}-Z_{1}\right) D-\left(N-\Psi\left(X_{1}, Y_{1}\right)\right)^{T} G\left(Y^{*}-Y_{1}\right) H\right) \\
& =\operatorname{tr}\left(\begin{array}{cc}
\left(M-\Phi\left(X_{1}, Y_{1}\right)\right)^{T} & 0 \\
0 & \left(N-\Psi\left(X_{1}, Y_{1}\right)\right)^{T}
\end{array}\right) \\
& \left.\left(\begin{array}{cc}
A\left(X^{*}-X_{1}\right) B-C\left(Y^{*}-Y_{1}\right) D & 0 \\
0 & E\left(X^{*}-X_{1}\right) F-G\left(Y^{*}-Y_{1}\right) H
\end{array}\right)\right) \\
& =\operatorname{tr}\left(\left(\begin{array}{cc}
M-\Phi\left(X_{1}, Y_{1}\right) & 0 \\
0 & N-\Psi\left(X_{1}, Y_{1}\right)
\end{array}\right)^{T}\left(\begin{array}{cc}
M-\Phi\left(X_{1}, Y_{1}\right) & 0 \\
0 & N-\Psi\left(X_{1}, Y_{1}\right)
\end{array}\right)\right) \\
& =\left\|R_{1}\right\|^{2} .
\end{aligned}
$$

Assume that (2.5) holds for $i=k$. When $i=k+1$, by Algorithm 2.1, we have that

$$
\begin{aligned}
\operatorname{tr}\left(\left(X^{*}-X_{k+1}\right)^{T} U_{k+1}\right. & \left.+\left(Y^{*}-Y_{k+1}\right)^{T} V_{k+1}\right) \\
=\operatorname{tr}\left(\left(X^{*}-X_{k+1}\right)^{T}[\right. & \frac{A^{T}\left(M-\Phi\left(X_{k+1}, Y_{k+1}\right)\right) B^{T}+E^{T}\left(N-\Psi\left(X_{k+1}, Y_{k+1}\right)\right) F^{T}}{2} \\
& +\frac{P A^{T}\left(M-\Phi\left(X_{k+1}, Y_{k+1}\right)\right) B^{T} Q+P E^{T}\left(N-\Psi\left(X_{k+1}, Y_{k+1}\right)\right) F^{T} Q}{2} \\
& \left.+\frac{\left\|R_{k+1}\right\|^{2}}{\left\|R_{k}\right\|^{2}} U_{k}\right]
\end{aligned}
$$


Journal of Applied Mathematics

$$
\begin{aligned}
& +\left(Y^{*}-Y_{k+1}\right)^{T}\left[\frac{-C^{T}\left(M-\Phi\left(X_{k+1}, Y_{k+1}\right)\right) D^{T}-G^{T}\left(N-\Psi\left(X_{k+1}, Y_{k+1}\right)\right) H^{T}}{2}\right. \\
& +\frac{-R C^{T}\left(M-\Phi\left(X_{k+1}, Y_{k+1}\right)\right) D^{T} S-R G^{T}\left(N-\Psi\left(X_{k+1}, Y_{k+1}\right)\right) H^{T} S}{2} \\
& \left.\left.+\frac{\left\|R_{k+1}\right\|^{2}}{\left\|R_{k}\right\|^{2}} V_{k}\right]\right) \\
& =\operatorname{tr}\left(\left(X^{*}-X_{k+1}\right)^{T}\left[A^{T}\left(M-\Phi\left(X_{k+1}, Y_{k+1}\right)\right) B^{T}+E^{T}\left(N-\Psi\left(X_{k+1}, Y_{k+1}\right)\right) F^{T}\right]\right. \\
& \left.+\left(Y^{*}-Y_{k+1}\right)^{T}\left[-C^{T}\left(M-\Phi\left(X_{k+1}, Y_{k+1}\right)\right) D^{T}-G^{T}\left(N-\Psi\left(X_{k+1}, Y_{k+1}\right)\right) H^{T}\right]\right) \\
& +\frac{\left\|R_{k+1}\right\|^{2}}{\left\|R_{k}\right\|^{2}} \operatorname{tr}\left(\left(X^{*}-X_{k+1}\right)^{T} U_{k}+\left(Y^{*}-Y_{k+1}\right)^{T} V_{k}\right) \\
& =\operatorname{tr}\left(\left(M-\Phi\left(X_{k+1}, Y_{k+1}\right)\right)^{T} A\left(X^{*}-X_{k+1}\right) B+\left(N-\Psi\left(X_{k+1}, Y_{k+1}\right)\right)^{T} E\left(X^{*}-X_{k+1}\right) F\right. \\
& \left.-\left(M-\Phi\left(X_{k+1}, Y_{k+1}\right)\right)^{T} C\left(Z^{*}-Z_{k+1}\right) D-\left(N-\Psi\left(X_{k+1}, Y_{k+1}\right)\right)^{T} G\left(Y^{*}-Y_{k+1}\right) H\right) \\
& +\frac{\left\|R_{k+1}\right\|^{2}}{\left\|R_{k}\right\|^{2}} \operatorname{tr}\left(\left(X^{*}-X_{k+1}\right)^{T} U_{k}+\left(Y^{*}-Y_{k+1}\right)^{T} V_{k}\right) \\
& =\operatorname{tr}\left(\begin{array}{cc}
\left(M-\Phi\left(X_{k+1}, Y_{k+1}\right)\right)^{T} & 0 \\
0 & \left(N-\Psi\left(X_{k+1}, Y_{k+1}\right)\right)^{T}
\end{array}\right) \\
& \left.\left(\begin{array}{cc}
A\left(X^{*}-X_{k+1}\right) B-C\left(Y^{*}-Y_{k+1}\right) D & 0 \\
0 & E\left(X^{*}-X_{k+1}\right) F-G\left(Y^{*}-Y_{k+1}\right) H
\end{array}\right)\right) \\
& +\frac{\left\|R_{k+1}\right\|^{2}}{\left\|R_{k}\right\|^{2}} \operatorname{tr}\left(\left(X^{*}-X_{k+1}\right)^{T} U_{k}+\left(Y^{*}-Y_{k+1}\right)^{T} V_{k}\right) \\
& =\operatorname{tr}\left(\begin{array}{cc}
\left(M-\Phi\left(X_{k+1}, Y_{k+1}\right)\right)^{T} & 0 \\
0 & \left(N-\Psi\left(X_{k+1}, Y_{k+1}\right)\right)^{T}
\end{array}\right) \\
& \left.\left(\begin{array}{cc}
M-\Phi\left(X_{k+1}, Y_{k+1}\right) & 0 \\
0 & N-\Psi\left(X_{k+1}, Y_{k+1}\right)
\end{array}\right)\right) \\
& +\frac{\left\|R_{k+1}\right\|^{2}}{\left\|R_{k}\right\|^{2}} \operatorname{tr}\left(\left(X^{*}-X_{k+1}\right)^{T} U_{k}+\left(Y^{*}-Y_{k+1}\right)^{T} V_{k}\right) \\
& =\left\|R_{k+1}\right\|^{2}+\frac{\left\|R_{k+1}\right\|^{2}}{\left\|R_{k}\right\|^{2}} \operatorname{tr}\left(\left(X^{*}-X_{k}\right)^{T} U_{k}+\left(Y^{*}-Y_{k}\right)^{T} V_{k}\right) \\
& -\frac{\left\|R_{k+1}\right\|^{2}}{\left\|U_{k}\right\|^{2}+\left\|V_{k}\right\|^{2}} \operatorname{tr}\left(U_{k}^{T} U_{k}+V_{k}^{T} V_{k}\right)=\left\|R_{k+1}\right\|^{2} .
\end{aligned}
$$


Therefore, (2.5) holds for $i=k+1$. Thus, (2.5) holds by the principal of induction. This completes the proof.

\section{Acknowledgments}

The authors are very much indebted to the anonymous referees and their editors for their constructive and valuable comments and suggestions which greatly improved the original copy of this paper. Grateful acknowledgements are given to Professor. Alain Miranville for his comments and suggestions that helped improve the second version of this paper greatly. This work was partially supported by the Research Fund Project (Natural Science 2010XJKYL018) and Natural Science Foundation of Sichuan Education Department (12ZB289) respectively. This work is also supported by Open Fund of Geomathematics Key Laboratory of Sichuan Province (scsxdz2011005) and Key Natural Science Foundation of Sichuan Education Department (12ZA008).

\section{References}

[1] H.-C. Chen, "Generalized reflexive matrices: special properties and applications," SIAM Journal on Matrix Analysis and Applications, vol. 19, no. 1, pp. 140-153, 1998.

[2] J. L. Chen and X. H. Chen, Special Matrices, Tsing Hua University Press, 2001.

[3] F. Li, X. Hu, and L. Zhang, "The generalized reflexive solution for a class of matrix equations $(A X=$ B, XC = D)," Acta Mathematica Scientia. Series B. English Edition, vol. 28, no. 1, pp. 185-193, 2008.

[4] M.-1. Liang and L.-F. Dai, "The left and right inverse eigenvalue problems of generalized reflexive and anti-reflexive matrices," Journal of Computational and Applied Mathematics, vol. 234, no. 3, pp. 743-749, 2010.

[5] Y. Yuan and H. Dai, "Generalized reflexive solutions of the matrix equation $A X B=D$ and an associated optimal approximation problem," Computers \& Mathematics with Applications, vol. 56, no. 6, pp. 1643-1649, 2008.

[6] J.-C. Zhang, S.-Z. Zhou, and X.-Y. Hu, "The $(P, Q)$ generalized reflexive and anti-reflexive solutions of the matrix equation $A X=B$," Applied Mathematics and Computation, vol. 209, no. 2, pp. 254-258, 2009.

[7] M. Dehghan and M. Hajarian, "An iterative algorithm for the reflexive solutions of the generalized coupled Sylvester matrix equations and its optimal approximation," Applied Mathematics and Computation, vol. 202, no. 2, pp. 571-588, 2008.

[8] M. Dehghan and M. Hajarian, "On the reflexive and anti-reflexive solutions of the generalised coupled Sylvester matrix equations," International Journal of Systems Science, vol. 41, no. 6, pp. 607625, 2010.

[9] Z.-Y. Peng, "New matrix iterative methods for constraint solutions of the matrix equation $A X B=C$," Journal of Computational and Applied Mathematics, vol. 235, no. 3, pp. 726-735, 2010.

[10] Z.-Y. Peng and X.-Y. Hu, "The reflexive and anti-reflexive solutions of the matrix equation $A X=B$, ," Linear Algebra and its Applications, vol. 375, pp. 147-155, 2003.

[11] Z.-H. Peng, X.-H. Hu, and L. Zhang, "An efficient algorithm for the least-squares reflexive solution of the matrix equation $A_{1} X B_{1}=C_{1}, A_{2} X B_{2}=C_{2}$," Applied Mathematics and Computation, vol. 181, no. 2, pp. 988-999, 2006.

[12] M. Dehghan and M. Hajarian, "An iterative method for solving the generalized coupled Sylvester matrix equations over generalized bisymmetric matrices," Applied Mathematical Modelling, vol. 34, no. 3, pp. 639-654, 2010.

[13] G. X. Huang, N. Wu, F. Yin, Z. L. Zhou, and K. Guo, “Finite iterative algorithms for solving generalized coupled Sylvester systems C Part I: one-sided and generalized coupled Sylvester matrix equations over generalized reflexive solutions," Applied Mathematical Modelling, vol. 36, pp. 15891603, 2012.

[14] A. L. Andrew, "Solution of equations involving centrosymmetric matrices," Technometrics, vol. 15, pp. 405-407, 1973. 
[15] I. J. Good, "The inverse of a centrosymmetric matrix," Technometrics, vol. 12, pp. 925-928, 1970.

[16] W. C. Pye, T. L. Boullion, and T. A. Atchison, "The pseudoinverse of a centrosymmetric matrix," vol. 6, pp. 201-204, 1973.

[17] J. R. Weaver, "Centrosymmetric (cross-symmetric) matrices, their basic properties, eigenvalues, and eigenvectors," The American Mathematical Monthly, vol. 92, no. 10, pp. 711-717, 1985.

[18] B. Kågström and L. Westin, "Generalized Schur methods with condition estimators for solving the generalized Sylvester equation," IEEE Transactions on Automatic Control, vol. 34, no. 7, pp. 745-751, 1989.

[19] F. Ding and T. Chen, "Iterative least-squares solutions of coupled Sylvester matrix equations," Systems $\mathcal{E}$ Control Letters, vol. 54, no. 2, pp. 95-107, 2005.

[20] F. Ding, P. X. Liu, and J. Ding, "Iterative solutions of the generalized Sylvester matrix equations by using the hierarchical identification principle," Applied Mathematics and Computation, vol. 197, no. 1, pp. 41-50, 2008.

[21] A. Kılıçman and Z. A. A. A. Zhour, "Vector least-squares solutions for coupled singular matrix equations," Journal of Computational and Applied Mathematics, vol. 206, no. 2, pp. 1051-1069, 2007.

[22] H. Dai, "On the symmetric solutions of linear matrix equations," Linear Algebra and its Applications, vol. 131, pp. 1-7, 1990.

[23] M. Dehghan and M. Hajarian, "An iterative algorithm for solving a pair of matrix equations $A Y B=E$, $C Y D=F$ over generalized centro-symmetric matrices," Computers $\mathcal{E}$ Mathematics with Applications. An International Journal, vol. 56, no. 12, pp. 3246-3260, 2008.

[24] M. Dehghan and M. Hajarian, "Analysis of an iterative algorithm to solve the generalized coupled Sylvester matrix equations," Applied Mathematical Modelling, vol. 35, no. 7, pp. 3285-3300, 2011.

[25] F. Ding and T. Chen, "On iterative solutions of general coupled matrix equations," SIAM Journal on Control and Optimization, vol. 44, no. 6, pp. 2269-2284, 2006.

[26] A.-P. Liao and Y. Lei, "Least-squares solution with the minimum-norm for the matrix equation $(A X B, G X H)=(C, D), "$ Computers $\mathcal{E}$ Mathematics with Applications, vol. 50, no. 3-4, pp. 539-549, 2005.

[27] X. Sheng and G. Chen, "An iterative method for the symmetric and skew symmetric solutions of a linear matrix equation $A X B+C Y D=E$," Journal of Computational and Applied Mathematics, vol. 233, no. 11, pp. 3030-3040, 2010.

[28] A.-G. Wu, G.-R. Duan, and Y. Xue, "Kronecker maps and Sylvester-polynomial matrix equations," IEEE Transactions on Automatic Control, vol. 52, no. 5, pp. 905-910, 2007.

[29] A.-G. Wu, G. Feng, G.-R. Duan, and W.-J. Wu, "Closed-form solutions to Sylvester-conjugate matrix equations," Computers $\mathcal{E}$ Mathematics with Applications, vol. 60, no. 1, pp. 95-111, 2010.

[30] F. Yin, G. X. Huang, and D. Q. Chen, "Finite iterative algorithms for solving generalized coupled Sylvester systems-Part II: two-sided and generalized coupled Sylvester matrix equations over reflexive solutions," Applied Mathematical Modelling, vol. 36, pp. 1604-1614, 2012.

[31] Q.-W. Wang, J.-H. Sun, and S.-Z. Li, "Consistency for bi(skew)symmetric solutions to systems of generalized Sylvester equations over a finite central algebra," Linear Algebra and its Applications, vol. 353, pp. 169-182, 2002.

[32] Q.-W. Wang, "Bisymmetric and centrosymmetric solutions to systems of real quaternion matrix equations," Computers \& Mathematics with Applications, vol. 49, no. 5-6, pp. 641-650, 2005.

[33] Q.-W. Wang, "A system of matrix equations and a linear matrix equation over arbitrary regular rings with identity," Linear Algebra and its Applications, vol. 384, pp. 43-54, 2004.

[34] X. W. Chang and J. S. Wang, "The symmetric solution of the matrix equations $A X+Y A=C, A X A^{T}+$ $B Y B^{T}=C$, and $\left(A^{T} X A, B^{T} X B\right)=(C, D), "$ Linear Algebra and its Applications, vol. 179, pp. 171-189, 1993.

[35] B. Zhou, Z.-Y. Li, G.-R. Duan, and Y. Wang, "Weighted least squares solutions to general coupled Sylvester matrix equations," Journal of Computational and Applied Mathematics, vol. 224, no. 2, pp. 759 776, 2009.

[36] A.-G. Wu, G. Feng, G.-R. Duan, and W.-J. Wu, "Iterative solutions to coupled Sylvester-conjugate matrix equations," Computers \& Mathematics with Applications, vol. 60, no. 1, pp. 54-66, 2010.

[37] A.-G. Wu, B. Li, Y. Zhang, and G.-R. Duan, "Finite iterative solutions to coupled Sylvester-conjugate matrix equations," Applied Mathematical Modelling. Simulation and Computation for Engineering and Environmental Systems, vol. 35, no. 3, pp. 1065-1080, 2011.

[38] A.-G. Wu, G. Feng, G.-R. Duan, and W.-J. Wu, "Finite iterative solutions to a class of complex matrix equations with conjugate and transpose of the unknowns," Mathematical and Computer Modelling, vol. 52, no. 9-10, pp. 1463-1478, 2010. 
[39] I. Jonsson and B. Kågström, "Recursive blocked algorithm for solving triangular systems. I. Onesided and coupled Sylvester-type matrix equations," Association for Computing Machinery. Transactions on Mathematical Software, vol. 28, no. 4, pp. 392-415, 2002.

[40] I. Jonsson and B. Kågström, "Recursive blocked algorithm for solving triangular systems. II. Two-sided and generalized Sylvester and Lyapunov matrix equations," Association for Computing Machinery, vol. 28, no. 4, pp. 416-435, 2002.

[41] T. Meng, "Experimental design and decision support," in Expert System, the Technology of Knowledge Management and Decision Making for the 21st Century, T. Leondes, Ed., vol. 1, Academic Press, 2001.

[42] G.-X. Huang, F. Yin, and K. Guo, "An iterative method for the skew-symmetric solution and the optimal approximate solution of the matrix equation $A X B=C$," Journal of Computational and Applied Mathematics, vol. 212, no. 2, pp. 231-244, 2008. 


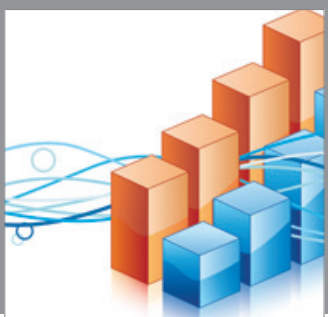

Advances in

Operations Research

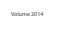

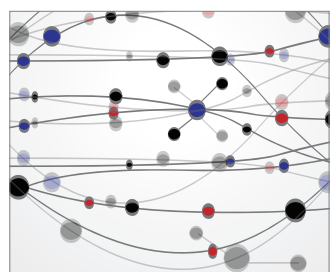

\section{The Scientific} World Journal
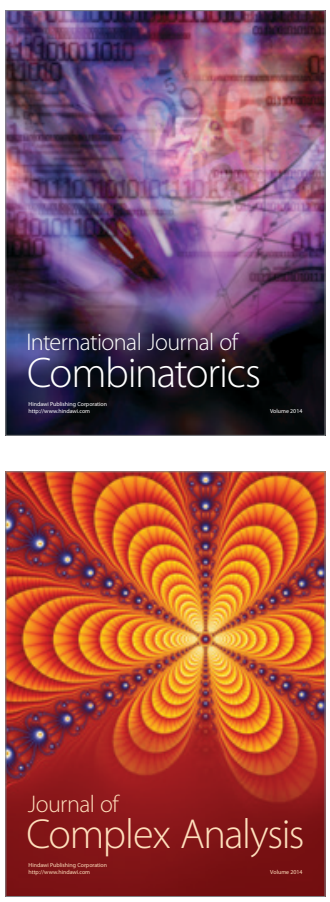

International Journal of

Mathematics and

Mathematical

Sciences
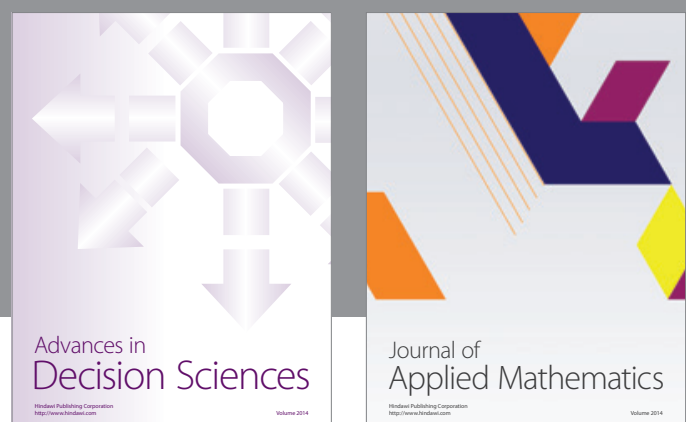

Journal of

Applied Mathematics
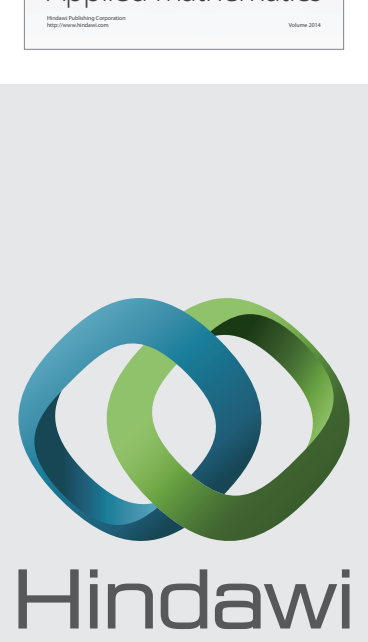

Submit your manuscripts at http://www.hindawi.com
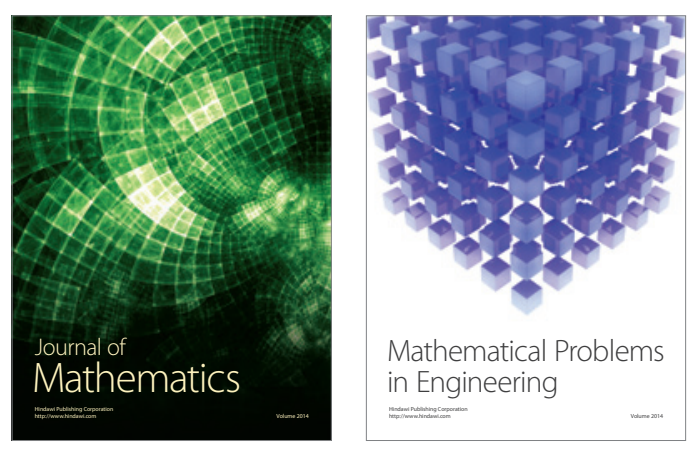

Mathematical Problems in Engineering
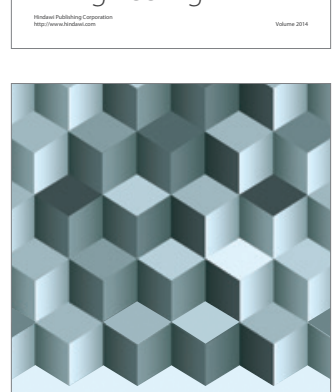

Journal of

Function Spaces
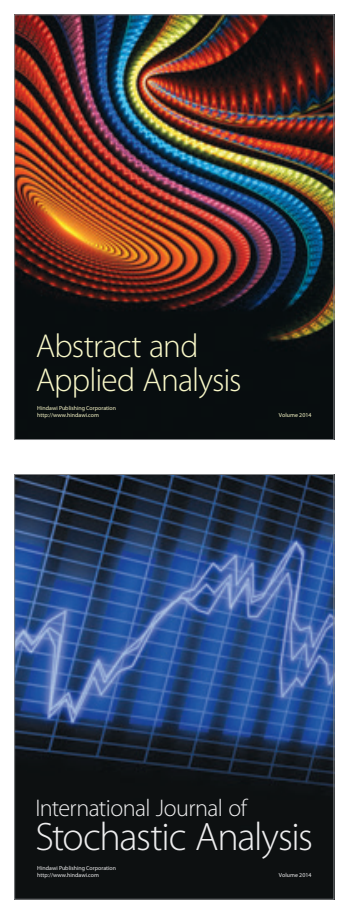

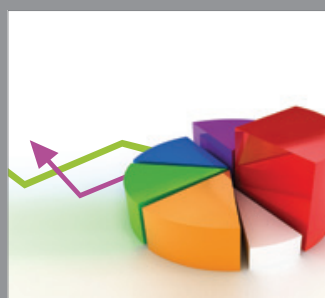

ournal of

Probability and Statistics

Promensencen
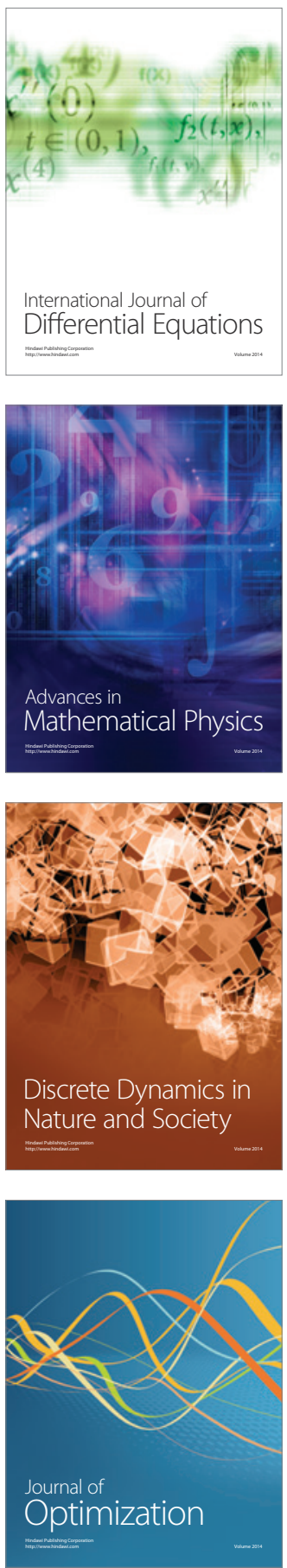